\begin{tabular}{|c|c|}
\hline Title & $\begin{array}{l}\text { Chronological study of oxygen isotope composition for the solar protoplanetary disk recorded in a fluffy Type A CA I } \\
\text { from V igarano }\end{array}$ \\
\hline Author(s) & Kawasaki, Noriyuki; Itoh, Shoichi; Sakamoto, Naoy a; Y urimoto, Hisay oshi \\
\hline Citation & $\begin{array}{l}\text { Geochimica et cosmochimica acta, 201, 83-102 } \\
\text { https://doi.org/10.1016/.gca.2015.12.031 }\end{array}$ \\
\hline Issue Date & 2017-03-15 \\
\hline Doc URL & http:/hdl.handle.net/2115/68264 \\
\hline Rights & $\begin{array}{l}\text { (9 2016 This manuscript version is made available under the CC-BY-NC-ND } 4.0 \text { license } \\
\text { http://creativecommons.org/icenses/by-nc-nd/4.0/ }\end{array}$ \\
\hline Rights(URL) & http://creativecommons.org/icenses/by-nc-nd/4.0/ \\
\hline Type & article (author version) \\
\hline File Information & V2-01final.pdf \\
\hline
\end{tabular}

Instructions for use 


\section{Chronological study of oxygen isotope composition for the solar protoplanetary disk recorded in a fluffy Type A CAI from Vigarano} Japan.

${ }^{\mathrm{b}}$ Department of Earth and Planetary Sciences, Kyoto University, Kyoto 606-8502, Japan.

${ }^{\mathrm{c}}$ Creative Research Institution, Hokkaido University, Sapporo 001-0021, Japan.

*corresponding author: Noriyuki Kawasaki

Address: Department of Natural History Sciences, Hokkaido University, Sapporo, 060-0810, Japan.

Tel: +81-11-706-9174

Email: kawasaki@ep.sci.hokudai.ac.jp

\section{ABSTRACT}

Fluffy Type A Ca-Al-rich inclusions (CAIs) containing reversely zoned melilite crystals are suggested to be direct condensates from solar nebular gas. We conducted an investigation of ${ }^{26} \mathrm{Al}-{ }^{26} \mathrm{Mg}$ systematics of a fluffy Type A CAI from Vigarano, named V2-01, with known oxygen isotopic distributions of reversely zoned melilite crystals; we also conducted oxygen isotope measurements of coexisting minerals. Two of six reversely zoned melilite crystals show continuous variations in magnesium isotopic composition, with $\delta^{25} \mathrm{Mg}$ becoming small along the inferred direction of crystal growth, which supports the idea that they originated through condensation. Petrography suggests that the constituent minerals of V2-01 formed in the following order: first spinel and fassaite enclosed by melilite, then reversely zoned melilite crystals, and spinel and diopside in the Wark-Lovering rim. The spinel enclosed by melilite has ${ }^{16} \mathrm{O}$-rich compositions $\left(\Delta^{17} \mathrm{O} \sim-24 \%\right.$ o $)$ and an initial value of $\left({ }^{26} \mathrm{Al} /{ }^{27} \mathrm{Al}\right)_{0}=(5.6 \pm 0.2) \times 10^{-5}$. The fassaite enclosed by melilite crystals shows variable oxygen isotopic compositions $\left(\Delta^{17} \mathrm{O} \sim-12 \%\right.$ and $\left.-17 \%\right)$ and plots on an isochron with $\left({ }^{26} \mathrm{Al} /{ }^{27} \mathrm{Al}\right)_{0}=(5.6 \pm 0.2) \times$ $10^{-5}$. The oxygen isotopic compositions of reversely zoned melilite showed continuous variations in $\Delta{ }^{17} \mathrm{O}$ along the inferred direction of crystal growth, suggesting that surrounding nebular gas, during the formation of the reversely zoned melilite, changed from ${ }^{16} \mathrm{O}$-poor $\left(\Delta^{17} \mathrm{O}\right.$ values larger than $-10 \%$ ) to ${ }^{16} \mathrm{O}$-rich $\left(\Delta^{17} \mathrm{O} \sim-25 \%\right)$. The six 
reversely zoned melilite crystals show indistinguishable initial ${ }^{26} \mathrm{Al} /{ }^{27} \mathrm{Al}$ values with an average $\left({ }^{26} \mathrm{Al} /{ }^{27} \mathrm{Al}\right)_{0}$ of $(4.7 \pm 0.3) \times 10^{-5}$, which is clearly distinguishable from the value of enclosed spinel and fassaite, indicating a younger formation age than the enclosed spinel and fassaite. The spinel and diopside from the Wark-Lovering rim shows ${ }^{16} \mathrm{O}$-rich compositions $\left(\Delta^{17} \mathrm{O} \sim-23 \%\right.$ o $)$ with $\left({ }^{26} \mathrm{Al} /{ }^{27} \mathrm{Al}\right)_{0}=(4.5 \pm 0.4) \times 10^{-5}$. The values of $\left({ }^{26} \mathrm{Al} /{ }^{27} \mathrm{Al}\right)_{0}$ are consistent with the formation sequence inferred from petrography. The formation period for the V2-01 CAI is estimated to be $0.18 \pm 0.07$ Myr from the difference in initial ${ }^{26} \mathrm{Al} /{ }^{27} \mathrm{Al}$ values. These data suggest that the oxygen isotopic composition of solar nebular gas surrounding the CAI changed from ${ }^{16} \mathrm{O}$-rich to ${ }^{16} \mathrm{O}$-poor and back to ${ }^{16} \mathrm{O}$-rich during the first $\sim 0.2 \mathrm{Myr}$ of Solar System formation.

\section{INTRODUCTION}

49

\section{$1.1{ }^{26} \mathrm{Al}-{ }^{26} \mathrm{Mg}$ systematics of fluffy Type A CAIs}

Ca-Al-rich inclusions (CAIs) in meteorites are the oldest objects in the Solar System, with an average age of $4567 \mathrm{Ma}$ according to U-corrected $\mathrm{Pb}-\mathrm{Pb}$ absolute chronology (Connelly et al., 2012). Many CAIs contained live ${ }^{26} \mathrm{Al}$, a short-lived radionuclide with 54 a half-life of $0.705 \mathrm{Myr}$ (Norris et al., 1983), at their formation (Lee et al., 1976; MacPherson et al., 1995). Whole-rock ${ }^{26} \mathrm{Al}-{ }^{26} \mathrm{Mg}$ isochron studies indicate the initial ${ }^{26} \mathrm{Al} /{ }^{27} \mathrm{Al}$ ratio $\left(\left({ }^{26} \mathrm{Al} /{ }^{27} \mathrm{Al}\right)_{0}\right)$ value of $(5.23 \pm 0.13) \times 10^{-5}$, called the canonical (Jacobsen et al., 2008; Larsen et al., 2011), which may reflect the $\left({ }^{26} \mathrm{Al} /{ }^{27} \mathrm{Al}\right)_{0}$ value at the time of Al-Mg fractionation of the CAIs or their precursors by evaporation and condensation processes (MacPherson et al., 2010, 2012). On the other hand, internal ${ }^{26} \mathrm{Al}-{ }^{26} \mathrm{Mg}$ mineral isochrons for CAIs, estimated using secondary ion mass spectrometry (SIMS), show a range of $\left({ }^{26} \mathrm{Al} /{ }^{27} \mathrm{Al}\right)_{0}$ values (Kita et al., 2012; MacPherson et al., 2012; Mishra and Chaussidon, 2014; Kawasaki et al., 2015), possibly representing a range of formation ages. The data of MacPherson et al. (2012) show that melted CAIs tend to be younger than unmelted CAIs, suggesting the CAI melting events continued for at least 0.2 Myr after the formation of CAI with the canonical ratio. CAI-chondrule compound objects show lower $\left({ }^{26} \mathrm{Al} /{ }^{27} \mathrm{Al}\right)_{0}$ values than most CAIs, suggesting that they have younger melting ages than CAIs; the melting events continued for at least 2.0 Myr after the CAI formation (Krot et al., 2005, 2007; Wakaki et al., 2011; MacPherson et al., 2012; Kawasaki et al., 2015). These inferred ages for the melting events of CAIs and CAI-chondrule compound objects likely correspond to ages of transient heating events that occurred in the early Solar System. 
73 determine the ages of condensation of their constituent minerals and formation periods

74 of the unmelted CAIs because their components may have been individually formed in

75 the solar nebula and then aggregated together into unmelted CAIs. However, very few

76 studies focus on the ages of individual components of condensate aggregates (e.g., Park

77 et al., 2014).

79 Reversely zoned melilite crystals have been found in fluffy Type A CAIs (a type of 80 unmelted CAI). These crystals have chemical compositions that become less 81 åkermanitic from the core to rim (MacPherson and Grossman, 1984). MacPherson and 82 Grossman (1984) suggested that the reversely zoned melilite crystals in fluffy Type A 83 CAIs were formed by direct condensation from nebular gas with decreasing pressure; 84 the fluffy Type A CAIs were never extensively melted. Therefore, the reversely zoned 85 melilite crystals and other constituent minerals were individually formed and 86 subsequently accreted together to form fluffy Type A CAIs. To determine the formation 87 period of fluffy Type A CAIs, a comparative study of the formation ages of individual 88 reversely zoned melilite crystals and other constituent minerals is conducted by their 89 individual ${ }^{26} \mathrm{Al}-{ }^{26} \mathrm{Mg}$ systematics using SIMS. Internal ${ }^{26} \mathrm{Al}-{ }^{26} \mathrm{Mg}$ isochrons may be 90 determined for individual reversely zoned melilite crystals because within the grains 91 there are significant chemical variations in ${ }^{27} \mathrm{Al} /{ }^{24} \mathrm{Mg}$ ratios.

92

93 In contrast to the condensation formation model for reversely zoned melilite crystals in

94 fluffy Type A CAIs, crystallization from incomplete melt with melt evaporation was 95 also suggested (Grossman et al., 2002). Significant mass dependent fractionation of 96 magnesium isotopes was expected for the melt evaporation processes by experimental 97 studies (Davis et al., 1990; Richter et al., 2002, 2007; Mendybaev et al., 2013) and 98 shown in Type B CAIs using SIMS (Bullock et al., 2013). Thus, the idea of 99 crystallization from incomplete melt with melt evaporation could be tested by changes 100 in the degree of magnesium isotopic fractionation along with the crystal growth of 101 reversely zoned melilite.

102

\section{$103 \quad 1.2$ Oxygen isotopes in fluffy Type A CAIs}

104 Phases in CAIs from CV chondrites have unequilibrated oxygen isotopic compositions 105 distributed along the carbonaceous chondrite anhydrous mineral (CCAM) line (Clayton 106 et al. 1977; Clayton 1993). Disequilibrium distributions of oxygen isotopes among 107 inter- and intra-crystals of CAIs have been observed through in situ analysis using 108 SIMS (e.g., Yurimoto et al., 1994; Yurimoto et al., 1998). The distributions of oxygen 
109 isotopic compositions of CAI minerals were suggested to be formed by thermal 110 processes in the solar protoplanetary disk within different oxygen isotopic environments 111 (Itoh and Yurimoto, 2003; Yurimoto and Kuramoto, 2004)—multiple melting (Yurimoto 112 et al., 1998; Ito et al., 2004; Itoh et al., 2004; Yoshitake et al., 2005; Aléon et al., 2007; 113 Krot et al., 2008; Yurimoto et al., 2008; Wakaki et al., 2013; Kawasaki et al., 2015), 114 condensation (Katayama et al., 2012; Kawasaki et al., 2012; Park et al., 2012), and 115 solid-state diffusion (Itoh and Yurimoto, 2003; Fagan et al., 2004) — as well as aqueous 116 and thermal metamorphism/alteration on the parent body (Wasson et al., 2001; Itoh et 117 al., 2004; Krot et al., 2008; Park et al., 2012; Kawasaki et al., 2015). A combination of 118 such processes may have led to the disequilibrium oxygen isotopic distributions 119 observed in CAIs, although most efficient processes are different for each mineral and 120 each CAI.

122 Oxygen isotopic compositions in reversely zoned melilite crystals in a fluffy Type A 123 CAI from Vigarano named V2-01 have been measured using SIMS with a line-profile 124 technique (Katayama et al., 2012). The oxygen isotopic compositions tend to gradually 125 become ${ }^{16} \mathrm{O}$-rich from cores to rims, indicating that the oxygen isotopic compositions of 126 surrounding nebular gas gradually changed from ${ }^{16} \mathrm{O}$-poor to ${ }^{16} \mathrm{O}$-rich during 127 condensation. Such trends for oxygen isotope distributions of melilite have also been 128 observed in other Type A CAIs from Allende and Efremovka (Kawasaki et al., 2012; 129 Park et al., 2012). In addition to the melilite, oxygen isotope measurements for other 130 minerals in fluffy Type A CAIs would assist in the understanding of the oxygen isotope 131 change in surrounding nebular gas during fluffy Type A CAI formation. Moreover, a 132 combined study of oxygen isotope and ${ }^{26} \mathrm{Al}-{ }^{26} \mathrm{Mg}$ systematics in a fluffy Type A CAI 133 would help determine the time scale of oxygen isotope change in the solar nebular gas.

135 In this study, we conducted oxygen isotope measurements and ${ }^{26} \mathrm{Al}-{ }^{26} \mathrm{Mg}$ systematics 136 using SIMS for V2-01, a fluffy Type A CAI from Vigarano (CV3). The chemical and 137 oxygen isotopic zoning of melilite crystals in V2-01 has already been studied by 138 Katayama et al. (2012). Preliminary measurements of the oxygen isotopic compositions 139 for minerals other than melilite were reported by Harazono and Yurimoto (2003) and 140 Yurimoto et al. (2008). The purposes of this study are (1) to determine the formation 141 period of the V2-01 fluffy Type A CAI, (2) to test the formation process of reversely 142 zoned melilite crystals in the fluffy Type A CAI, (3) to determine the oxygen isotope 143 change during V2-01 CAI formation, and (4) to investigate time scale of oxygen isotope 144 change in nebular gas. 


\section{EXPERIMENTAL}

\subsection{Sample preparation and elemental analysis}

149 The fluffy Type A CAI, V2-01, is included in a polished thin section of the Vigarano

150 CV3 carbonaceous chondrite. The polished thin section was coated with a thin $(\sim 20 \mathrm{~nm})$

151 carbon coat for backscattered electron (BSE) imaging and an elemental analysis using

152 an energy dispersive X-ray spectrometer (EDS), oxygen isotope measurements using

153 SIMS, and $\mathrm{Al}-\mathrm{Mg}$ isotope measurements using SIMS with a peak jumping mode. In

154 addition, the carbon coated section was overlaid with a gold thin film $(\sim 70 \mathrm{~nm})$ for $\mathrm{Al}^{-}$

$155 \mathrm{Mg}$ isotope measurements using SIMS in multicollection mode. The gold coating allows

156 for a better stability for secondary ion emission for an intense primary beam than the

157 carbon coating, which results in higher precision and accuracy in measurement results.

159 BSE images were obtained using a field emission type scanning electron microscope 160 (FE-SEM; JEOL JSM-7000F) at Hokkaido University. Quantitative elemental analysis 161 and X-ray elemental mapping were conducted using an energy dispersive spectrometer 162 (EDS, Oxford X-Max 150) installed on the FE-SEM. A $15 \mathrm{keV}$ electron beam probe 163 with currents of $0.3 \mathrm{nA}$ (for quantitative analysis) and $5 \mathrm{nA}$ (for mapping) was 164 employed in our study.

167 Oxygen isotopic compositions of the minerals in V2-01 were measured using a SIMS 168 instrument (Cameca ims-1280HR) of Hokkaido University. $\mathrm{A}^{133} \mathrm{Cs}^{+}$primary beam (20 $169 \mathrm{keV}, 200 \mathrm{pA}$ ) with a diameter of $10 \mu \mathrm{m}$ was used for oxygen isotope measurements of 170 diopside, fassaite, and spinel. Negative secondary ions $\left({ }^{16} \mathrm{O}^{-},{ }^{17} \mathrm{O}^{-}\right.$, and $\left.{ }^{18} \mathrm{O}^{-}\right)$were 171 measured. A normal incident electron flood gun was used for the electrostatic charge 172 compensation of the analyzing area during the measurements. ${ }^{16} \mathrm{O}^{-}$was measured using 173 a Faraday cup, while ${ }^{17} \mathrm{O}^{-}$and ${ }^{18} \mathrm{O}^{-}$were measured using an electron multiplier with the 174 peak jumping mode of a sector magnet. The mass resolution of $M / \Delta M$ was set at $\sim 6000$ 175 to ensure that the contribution of ${ }^{16} \mathrm{OH}^{-}$to ${ }^{17} \mathrm{O}^{-}$is negligible. The secondary ion intensity 176 of ${ }^{16} \mathrm{O}^{-}$was $\sim 1 \times 10^{8} \mathrm{cps}$. Each measurement was conducted for 30 cycles of a counting 177 sequence with ${ }^{16} \mathrm{O}^{-}$for $1 \mathrm{~s},{ }^{17} \mathrm{O}^{-}$for $2 \mathrm{~s}$, and ${ }^{18} \mathrm{O}^{-}$for $1 \mathrm{~s}$. Russian spinel $\left(\delta^{17} \mathrm{O}=4.42 \%\right.$, $178 \delta^{18} \mathrm{O}=8.50 \%$; Yurimoto et al., 1994) was used as a standard to correct the instrumental 179 mass fractionation. 


\subsection{Magnesium isotope analysis in multicollection mode}

182 Magnesium isotopes and ${ }^{27} \mathrm{Al} /{ }^{24} \mathrm{Mg}$ isotope ratios of the minerals in $\mathrm{V} 2-01$ were 183 measured using a SIMS instrument (Cameca ims-1280HR) of Hokkaido University. An $184{ }^{16} \mathrm{O}^{-}$primary beam accelerated to $23 \mathrm{keV}$ was employed in the experiment. We used 185 both the peak-jumping mode and the multicollection mode, depending on the secondary 186 ion intensities of magnesium isotopes from the minerals. For diopside, fassaite, and 187 spinel, the magnesium isotopes $\left({ }^{24} \mathrm{Mg}^{+},{ }^{25} \mathrm{Mg}^{+}\right.$, and $\left.{ }^{26} \mathrm{Mg}^{+}\right)$and ${ }^{27} \mathrm{Al}^{+}$were measured 188 simultaneously in the multicollection mode with four Faraday cups: ${ }^{24} \mathrm{Mg}^{+}$for $\mathrm{L} 2^{*}\left(10^{11}\right.$ $\Omega),{ }^{25} \mathrm{Mg}^{+}$for $\mathrm{L} 1\left(10^{11} \Omega\right),{ }^{26} \mathrm{Mg}^{+}$for $\mathrm{H} 1\left(10^{11} \Omega\right)$, and ${ }^{27} \mathrm{Al}^{+}$for $\mathrm{H} 2 *\left(10^{10} \Omega\right)$. The 190 primary beam current was set to $7 \mathrm{nA}$ with an elliptical shape of $6 \times 12 \mu \mathrm{m}$ for the 191 diopside and spinel measurements, while the primary beam current was set to $10 \mathrm{nA}$ 192 with an elliptical shape of $5 \times 9 \mu \mathrm{m}$ for measurements of the fassaite measurements. The 193 mass resolution of $M / \Delta M$ was set at $\sim 2000$. The contributions of ion interferences (e.g., $194{ }^{48} \mathrm{Ca}^{2+},{ }^{24} \mathrm{MgH}^{+},{ }^{25} \mathrm{MgH}^{+}$, and $\left.{ }^{52} \mathrm{Cr}^{2+}\right)$ were negligible under these conditions. The 195 secondary ion intensities of ${ }^{24} \mathrm{Mg}^{+}$were typically $1.1 \times 10^{8}, 7.5 \times 10^{7}$, and $1.5 \times 10^{8} \mathrm{cps}$ 196 for diopside, fassaite, and spinel, respectively. Each measurement was conducted with 20 cycles of counting the secondary ions for $10 \mathrm{~s}$.

200 The excess radiogenic ${ }^{26} \mathrm{Mg}, \delta^{26} \mathrm{Mg}^{*}$, was calculated using an exponential fractionation law with the coefficient $\alpha_{\text {natural }}=0.5128$, because natural fractionation for magnesium isotopes is considered to be controlled by evaporation processes (Davis et al., 2015). However, the natural mass fractionation deviates from the instrumental mass fractionation of SIMS, which differs among target minerals under the measurement conditions (Itoh et al., 2008). Thus, we determined the instrumental mass fractionation, $\alpha_{\text {SIMS }}$, through measurements of Takashima augite, synthetic fassaite glass, and Russian spinel for each mineral, to calculate the excess radiogenic ${ }^{26} \mathrm{Mg}$. The $\alpha_{\text {SIMS }}$ for spinel was determined through the linear regression of the $\Phi^{25} \mathrm{Mg}$ and $\Phi^{26} \mathrm{Mg}$ values of Takashima augite and Russian spinel, while the $\alpha_{S I M S}$ for fassaite and diopside was determined through the linear regressions of the $\Phi^{25} \mathrm{Mg}$ and $\Phi^{26} \mathrm{Mg}$ values of Takashima augite and synthetic fassaite glass, where $\Phi^{25,26} \mathrm{Mg}=1000 \times \ln$ $\left.\left[{ }^{25,26} \mathrm{Mg} /{ }^{24} \mathrm{Mg}\right)_{\text {sample }} /{ }^{25,26} \mathrm{Mg} /{ }^{24} \mathrm{Mg}\right)_{\text {ref. }}$. . The terrestrial reference ratios of $\left({ }^{25} \mathrm{Mg} /{ }^{24} \mathrm{Mg}\right)_{\text {ref. }}$.

$=0.12663$ and ( $2 \mathrm{Mg} / \mathrm{Mg}$ ref. $=0.13932$ (Catanzaro et al., 1966) were used, although

213 the final corrected- $\delta^{26} \mathrm{Mg} *$ values are independent of reference ratios. The $\alpha_{\text {SIMS }}$ values 214 are not only different among minerals but also different among measurement sessions 215 for the same mineral. We therefore determined the $\alpha_{\text {SIMS }}$ values for each mineral in 216 every measurement session. In this study, the $\alpha_{\text {SIMS }}$ for spinel was determined as $0.531 \pm$ 
2170.004 and $0.515 \pm 0.004$ for two different sessions, the $\alpha_{\text {SIMS }}$ for diopside was 218 determined as $0.493 \pm 0.009$, and the $\alpha_{\text {SIMS }}$ for fassaite was determined as $0.488 \pm 0.006$ $219(2 \sigma)$. From the results of the linear regressions, an instrumental offset for the $\delta^{26} \mathrm{Mg}^{*}$ 220 values, $\beta$, which ranged from +0.44 to +1.19 with $2 \sigma$ errors of $0.02-0.08$ depending on 221 minerals and analytical sessions, was identified. The corrected $\delta^{26} \mathrm{Mg}^{*}$ values were 222 determined by the following equation

$$
\begin{gathered}
\delta^{26} \mathrm{Mg}^{*}=\delta^{26} \mathrm{Mg}_{\text {sample }}-\left[\left(1+\frac{\delta^{25} \mathrm{Mg}_{\text {sample }}}{1000}\right)^{\frac{1}{\alpha_{\text {natural }}}}-1\right] \times 1000 \\
-\beta+\left[\left(1+\frac{\delta^{25} \mathrm{Mg}_{\text {std }}}{1000}\right)^{\frac{1}{\alpha_{\text {natural }}}}-1\right] \times 1000 \\
-\left[\left(1+\frac{\delta^{25} \mathrm{Mg}_{\text {std }}}{1000}\right)^{\frac{1}{\alpha_{\text {SIMS }}}}-1\right] \times 1000,
\end{gathered}
$$

223 where $\delta^{25,26} \mathrm{Mg}_{\text {sample }}=\left[\left({ }^{25,26} \mathrm{Mg} /{ }^{24} \mathrm{Mg}\right)_{\text {sample }} /\left({ }^{25,26} \mathrm{Mg} /{ }^{24} \mathrm{Mg}\right)_{\text {ref. }}-1\right] \times 1000$ and $\delta^{25} \mathrm{Mg}_{\text {std }}$ $224=\left[\left({ }^{25} \mathrm{Mg} /{ }^{24} \mathrm{Mg}\right)_{\text {std }} /\left({ }^{25} \mathrm{Mg} /{ }^{24} \mathrm{Mg}\right)_{\text {ref. }}-1\right] \times 1000$. The first and second terms on the 225 right-hand side of the equation was transformed into $\delta^{26} \mathrm{Mg}^{*}$ sample, and as a result, the 226 equation would be finally expressed as

$$
\begin{aligned}
\delta^{26} \mathrm{Mg}^{*}=\delta^{26} \mathrm{Mg}_{\text {sample }}^{*}-\beta+\left[\left(1+\frac{\delta^{25} \mathrm{Mg}_{\text {std }}}{1000}\right)^{\frac{1}{\alpha_{\text {natural }}}}-1\right] \times 1000 \\
-\left[\left(1+\frac{\delta^{25} \mathrm{Mg}_{\text {std }}}{1000}\right)^{\frac{1}{\alpha_{\text {SIMS }}}}-1\right] \times 1000 .
\end{aligned}
$$

227 A standard error of the mean of 20 cycles in a single analysis of $\delta^{26} \mathrm{Mg}^{*}$ sample was 228 applied for estimating the analytical errors of final corrected- $\delta^{26} \mathrm{Mg} *$ values. If the 229 standard errors of both $\delta^{25} \mathrm{Mg}_{\text {sample }}$ and $\delta^{26} \mathrm{Mg}_{\text {sample }}$ were independently used for 230 estimating the final analytical error, the final analytical error would be overestimated 231 because the standard errors of $\delta^{25} \mathrm{Mg}_{\text {sample }}$ and $\delta^{26} \mathrm{Mg}_{\text {sample }}$ are usually larger than 232 statistical errors calculated from total ion counts in the measurement condition due to an 233 instrumental mass fractionation during the 20 cycle measurement. In contrast, the 234 standard error of $\delta^{26} \mathrm{Mg}^{*}$ sample, which is much less affected by the instrumental mass 235 fractionation during the measurement, is comparable to the statistical error. Thus, we 236 use the standard error of $\delta^{26} \mathrm{Mg}^{*}$ sample instead of those of $\delta^{25} \mathrm{Mg}_{\text {sample }}$ and $\delta^{26} \mathrm{Mg}_{\text {sample }}$ for 237 estimating the final analytical error. An analytical error of $\delta^{25} \mathrm{Mg}_{\text {std }}$ was assigned as a 
238 standard error of repetitive measurements of terrestrial standards. The errors of $239 \delta^{26} \mathrm{Mg}^{*}$ sample $, \delta^{25} \mathrm{Mg}_{\text {std }}, \alpha_{\text {natural }}, \alpha_{\text {SIMS }}$, and $\beta$ were used for estimating the final analytical 240 error for each spot through propagation of the errors. The error of $\alpha_{\text {natural }}$ was negligible

241 for the measurement conditions used. The analytical errors (2 sigma) for $\delta^{26} \mathrm{Mg}$ * 242 range from 0.09 to $0.16 \%$.

243

244 The relative sensitivity factor for aluminum and magnesium was determined for each 245 mineral through Takashima augite, synthetic fassaite glass, and Russian spinel 246 measurements for diopside, fassaite, and spinel, respectively. The instrumental mass 247 fractionations for Takashima augite and synthetic fassaite glass were distinct from each 248 other in our measurement conditions. The instrumental mass fractionations for diopside 249 and fassaite in V2-01 may also have varied with the chemical compositions under the 250 same measurement conditions. Thus, the $\delta^{25} \mathrm{Mg}$ values for diopside and fassaite were 251 not determined in this study. On the other hand, the systematic errors of $\delta^{25} \mathrm{Mg}$ were 252 negligible to determine the $\delta^{26} \mathrm{Mg}^{*}$ because the statistical errors of $\delta^{26} \mathrm{Mg}^{*}$ sample on the 253 measurements were dominant in the uncertainty of the calculated $\delta^{26} \mathrm{Mg}^{*}$ values using 254 Eq. (2). Therefore, the $\delta^{26} \mathrm{Mg}^{*}$ values were correctly calculated within errors shown in 255 Table 3. The $\delta^{25} \mathrm{Mg}$ values for spinel in V2-01 were estimated assuming that $\delta^{25} \mathrm{Mg}$ of 256 Russian spinel is 0.

\subsection{Magnesium isotope analysis in peak-jumping mode}

260 For melilite, magnesium isotopes $\left({ }^{24} \mathrm{Mg}^{+},{ }^{25} \mathrm{Mg}^{+}\right.$, and $\left.{ }^{26} \mathrm{Mg}^{+}\right)$were measured using an electron multiplier, while ${ }^{27} \mathrm{Al}^{+}$was measured using a Faraday cup with the peak jumping mode of a sector magnet. The ${ }^{16} \mathrm{O}^{-}$primary beam accelerated to $23 \mathrm{keV}$ was used and the secondary ion intensity of ${ }^{24} \mathrm{Mg}^{+}$was set to $3 \times 10^{5}$ cps under a mass resolution of $M / \Delta M$ of $\sim 3500$, which is sufficient to resolve $\mathrm{Mg}$ hydrate interferences at masses 25 and 26. Because melilite crystals in V2-01 exhibit chemical zonation, the primary beam current was adjusted to maintain constant ${ }^{24} \mathrm{Mg}^{+}$intensity for each spot according to the chemical compositions in order to compensate dead time correction of the electron multiplier. Under this condition, the primary beam current was ranged from 0.2 to $1.0 \mathrm{nA}$ with a diameter of 3 to $5 \mu \mathrm{m}$. Each measurement was conducted for 50 cycles of a counting sequence with ${ }^{24} \mathrm{Mg}^{+}$for $3 \mathrm{~s},{ }^{25} \mathrm{Mg}^{+}$for $10 \mathrm{~s},{ }^{26} \mathrm{Mg}^{+}$for $10 \mathrm{~s}$, and ${ }^{27} \mathrm{Al}^{+}$for $1 \mathrm{~s}$. The analytical errors for $\delta^{26} \mathrm{Mg}^{*}$ were assigned as internal errors (2SE) and

272 factor for aluminum and magnesium were determined through measurements of 273 synthetic melilite glass. The calculation methods were the same as those described in 


\section{RESULTS}

\subsection{Petrographic description}

279

The CAI V2-01 is a fluffy Type A CAI from the Vigarano CV3 with a size of $\sim 7 \mathrm{~mm}$ across (Fig. 1). A detailed petrographic description of V2-01 and chemical and oxygen isotopic distributions in reversely zoned melilite crystals have been presented by Katayama et al. (2012). The CAI is mainly composed of melilite in addition to spinel, fassaite, hibonite, perovskite, and Fe-metal as accessory minerals. Anorthite is present as a secondary alteration product replacing melilite. Melilite is abundant throughout the inclusion, with crystal sizes of $\sim 50$ to $600 \mu \mathrm{m}$. Some melilite crystals contain spinel crystals with sizes of a few micrometers to tens of micrometers; a few spinel crystals are attached to hibonite and/or perovskite. Two types of fassaite are present in V2-01: lath-shaped, <1 $\mu \mathrm{m}$ grains; and anhedral crystals from several microns to $\sim 30 \mu \mathrm{m}$, within the melilite crystals. The rounded anhedral crystals are often attached to perovskite grains.

V2-01 has an irregular, "fluffy" shape and a Wark-Lovering (W-L) rim (Wark and 293 Lovering, 1977) surrounding the entire CAI. A forsterite accretionary rim is also 294 observed outside the W-L rim (Fig. 2), which has layers, from innermost to outermost, 295 of melilite, spinel, anorthite, and diopside. Perovskite grains are often attached to spinel crystals in the W-L rim. The W-L rim minerals and the forsterite accretionary rim also occur in the CAI interior due to the highly indented, irregular rim shape of the CAI.

Spinel grains in both the CAI interior and W-L rim typically have $\mathrm{FeO}$ contents of less than 0.3 wt $\%$ and $\mathrm{Fe} /(\mathrm{Mg}+\mathrm{Fe})$ ratios less than 0.01 . Only spinels with such low $\mathrm{FeO}$ contents were measured by SIMS for the ${ }^{26} \mathrm{Al}-{ }^{26} \mathrm{Mg}$ systematics in this study. In contrast, rims of spinel grains in the W-L rim and the small spinel grains in the W-L rim with sizes of less than $\sim 5 \mu \mathrm{m}$ show high $\mathrm{FeO}$ contents, up to $\sim 5 \mathrm{wt} \%$. Spinel grains with sizes of $\sim 3 \mu \mathrm{m}$ have Mg-rich cores and Fe-rich rims (Fig. 2c). In this study, spinels the primary beam size used, $6 \times 12 \mu \mathrm{m}$, was larger than the grains. Representative chemical compositions of minerals are shown in Table 1.

\subsection{Chemical and oxygen isotopic zoning of reversely zoned melilite crystals}


310 Katayama et al. (2012) determined the oxygen isotopic compositions of nine reversely 311 zoned melilite crystals from V2-01. In the present study, we determined the ${ }^{26} \mathrm{Al}-{ }^{26} \mathrm{Mg}$ 312 systematics for six (grains 1, 3, 8, 9, 15, and 21) of those nine grains. Four (grains 1, 9, 313 15, and 21) were adjacent to the W-L rim and the other two grains (grains 3 and 8) were 314 not. We resummarize the descriptions of the chemical and oxygen isotopic zoning of six reversely zoned melilite crystals below. Data of chemical and oxygen isotopic distributions for Figures 3 and 4 were obtained by Katayama et al. (2012).

318 Grain 1 (Fig. 3a) is $200 \times 400 \mu \mathrm{m}$ and is adjacent to the W-L rim. It exhibited reverse 319 zoning from the core $(\sim \AA k$ 30) to the rim ( $\AA \mathrm{k} 4)$, although highly gehlenitic compositions $(<\sim \AA \mathrm{k} 6)$ are only present at the W-L rim side. The chemical zoning pattern appears to be continuous with an adjacent grain, suggesting parallel growth (Fig. 3a). A variation in oxygen isotopic composition is observed in a zone with the chemical composition ranging from $\sim \AA \mathrm{k} 6$ to $\sim \AA \mathrm{k} 5$ (Fig. 4a). The oxygen isotopic composition is homogeneously distributed in the grain interior $\left(\Delta^{17} \mathrm{O} \sim-6 \%\right.$ ) despite reverse zoning, but changes gradually towards ${ }^{16} \mathrm{O}$-rich from $\sim \AA \mathrm{k} 6$ and reaches $\Delta^{17} \mathrm{O} \sim-25 \%$ near the $\operatorname{rim}(\sim \AA ̊ 丿 \mathrm{k} 5)$.

Grain 3 (Fig. 3b) is $250 \times 300 \mu \mathrm{m}$ and is not attached to the W-L rim. It exhibits reverse zoning from the core $(\sim \AA k$ 21) to the rim $(\sim \AA k$ 5), and its isotopic composition is homogeneous $\left(\Delta^{17} \mathrm{O} \sim-5 \%\right)$.

Grain 8 is $150 \times 200 \mu \mathrm{m}$ and is not attached to the W-L rim. Half of the crystal is shown in Fig. 3c. The grain is reversely zoned from the core $(\sim \AA \mathrm{k} 15)$ to the rim $(\sim \AA \mathrm{k} k 5)$. The line profiles of oxygen isotopic compositions along the inferred direction of crystal growth (reverse zoning in chemical composition) (Fig. 4b) show that the oxygen isotopic composition is homogeneous in the grain interior $\left(\Delta^{17} \mathrm{O} \sim-13 \%\right.$ ) despite reverse chemical zoning. The composition changes gradually towards ${ }^{16} \mathrm{O}$-rich from

340 Grain 9 is $300 \times 600 \mu \mathrm{m}$ and is adjacent to the W-L rim. Half of the crystal is shown in 341 Fig. 3d. It exhibits reverse zoning from the core ( $\AA \mathrm{k} 18)$ to the rim $(\sim \AA \mathrm{k} k 5)$. A variation 342 in the oxygen isotopic composition is observed in a zone with the chemical composition

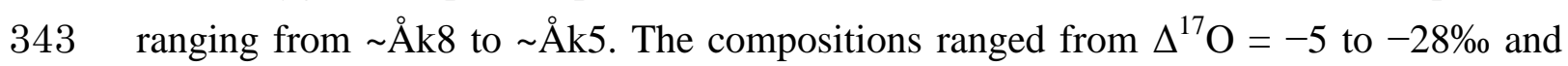
344 change from ${ }^{16} \mathrm{O}$-poor to ${ }^{16} \mathrm{O}$-rich composition along the inferred direction of crystal 345 growth. 
347 Grain 15 (Fig. 3e) is $80 \times 150 \mu \mathrm{m}$ and is adjacent to the W-L rim. It exhibits reverse 348 zoning from the core $(\sim \AA \mathrm{k} 20)$ to the rim ( $\AA \mathrm{k} 3)$, although highly gehlenitic 349 compositions $(<\sim \AA$ A 8$)$ are only present near the W-L rim. A variation in the oxygen 350 isotopic composition is observed in a zone with chemical composition ranging from $351 \sim \AA$ k 6 to $\sim \AA \mathrm{k} 3$. The oxygen isotopic composition is homogeneously ${ }^{16} \mathrm{O}$-poor in the 352 grain interior $\left(\Delta^{17} \mathrm{O} \sim-7 \%\right.$ ) despite reverse zoning, but it changes gradually towards ${ }^{16} \mathrm{O}$-rich from $\sim \AA \mathrm{k} 6$ and reaches $\Delta^{17} \mathrm{O} \sim-16 \%$ near the rim $(\sim \AA \mathrm{k} 3)$.

355 Grain 21 (Fig. 3f) is $80 \times 120 \mu \mathrm{m}$ and is adjacent to the W-L rim. It exhibits reverse zoning from the core $(\sim \AA \mathrm{k} 24)$ to the rim $(\sim \AA \mathrm{k} 2)$, although highly gehlenitic compositions $(<\sim \AA \mathrm{k} 6)$ are only present at the W-L rim side of the grain. A variation in oxygen isotopic composition is observed in a zone with chemical composition ranging from $\sim \AA \mathrm{k} 5$ to $\sim \AA \mathrm{k} 2$. The isotopic composition is homogeneously ${ }^{16} \mathrm{O}$-poor at the grain interior $\left(\Delta^{17} \mathrm{O} \sim-8 \%\right.$ ) despite reverse chemical zoning, but it changes gradually towards ${ }^{16}$ O-rich from $\sim \AA$ k 5 and reaches $\Delta^{17} \mathrm{O} \sim-20 \%$ near the rim $(\sim \AA \mathrm{k} 2)$.

\subsection{Oxygen and $\mathrm{Al}-\mathrm{Mg}$ isotopic compositions of diopside, fassaite, and spinel}

The oxygen and magnesium isotopic compositions and ${ }^{27} \mathrm{Al} /{ }^{24} \mathrm{Mg}$ ratios for diopside, fassaite, and spinel in V2-01 are summarized in Tables 2 and 3. The oxygen isotopic compositions of spinel in the CAI interior enclosed by melilite crystals, fassaite enclosed by melilite crystals, and diopside and spinel in the W-L rim are plotted on the CCAM line in Fig. 5. The spinel in CAI interior has ${ }^{16} \mathrm{O}$-rich compositions of $\Delta^{17} \mathrm{O} \sim$ $-24 \%$, while the minerals in the W-L rim has homogeneously ${ }^{16} \mathrm{O}$-rich compositions of $\Delta^{17} \mathrm{O} \sim-23 \%$. On the other hand, the fassaite grains enclosed by melilite showed two distinct oxygen isotopic compositions, one grain with $\Delta^{17} \mathrm{O} \sim-17 \%$, while other three grains have $\Delta^{17} \mathrm{O} \sim-12 \%$.

Figure 6 shows the magnesium isotopic compositions and ${ }^{27} \mathrm{Al} /{ }^{24} \mathrm{Mg}$ ratios of minerals plotted on the ${ }^{26} \mathrm{Al}-{ }^{26} \mathrm{Mg}$ isochron diagram. The spinel measured in CAI interior has an excess ${ }^{26} \mathrm{Mg}$, with $\delta^{26} \mathrm{Mg}^{*} \sim 0.98 \pm 0.09 \%$ (2SD, $n=12$ ). On the other hand, the spinel measured in the W-L rim shows a $\delta^{26} \mathrm{Mg} *$ of $\sim 0.77 \pm 0.07 \%$ o (2SD, $n=9$ ), which is clearly smaller than that for the CAI interior. If we define a model isochron of the spinel in the CAI interior assuming initial $\left(\delta^{26} \mathrm{Mg}^{*}\right)_{0}=-0.0159 \pm 0.0014 \%$ o (Larsen et al., $2011)$, the spinel in the CAI interior would have $\left({ }^{26} \mathrm{Al} /{ }^{27} \mathrm{Al}\right)_{0}=(5.6 \pm 0.2) \times 10^{-5}$. 
The minerals of the W-L rim have the same oxygen isotopic compositions, indicating sequential formation in the same gaseous reservoir, which satisfies a condition to generate an internal mineral isochron. The mineral isochron gives $\left({ }^{26} \mathrm{Al} /{ }^{27} \mathrm{Al}\right)_{0}=(4.5 \pm$ $0.4) \times 10^{-5}$ and $\left(\delta^{26} \mathrm{Mg}^{*}\right)_{0}=-0.05 \pm 0.05 \%$ for diopside and spinel in the W-L rim. Chronological validities of these isochrons are discussed in later sections. The $\mathrm{Al}-\mathrm{Mg}$ isotopic compositions for fassaite plot on the model isochron for spinel in the CAI interior and are resolved from the isochron for minerals in the W-L rim (Fig. 6).

\subsection{Al-Mg isotopic compositions of reversely zoned melilite crystals}

391

The magnesium isotopic compositions and ${ }^{27} \mathrm{Al} /{ }^{24} \mathrm{Mg}$ ratios for the reversely zoned melilite crystals in V2-01 are summarized in Table 4. Figure 7 shows the magnesium isotopic compositions and ${ }^{27} \mathrm{Al} /{ }^{24} \mathrm{Mg}$ ratios of each grain plotted on ${ }^{26} \mathrm{Al}-{ }^{26} \mathrm{Mg}$ isochron diagrams. As described earlier, the oxygen isotopic compositions changed during crystal growth. Nevertheless, all data for a given crystal plot on a straight line, suggesting contemporaneous formation. The isochron of grain 1 gave an initial value of $\left({ }^{26} \mathrm{Al} /{ }^{27} \mathrm{Al}\right)_{0}$ $=(4.6 \pm 0.3) \times 10^{-5}$ and $\left(\delta^{26} \mathrm{Mg} *\right)_{0}=0.5 \pm 0.7 \%$ (Fig. 7a), grain 3 gave $\left({ }^{26} \mathrm{Al}{ }^{27} \mathrm{Al}\right)_{0}=$ $(4.7 \pm 0.6) \times 10^{-5}$ and $\left(\delta^{26} \mathrm{Mg} *\right)_{0}=0.1 \pm 1.0 \%$ (Fig. $\left.7 \mathrm{~b}\right)$, grain 8 gave $\left({ }^{26} \mathrm{Al}{ }^{27} \mathrm{Al}\right)_{0}=(4.6$ $\pm 0.4) \times 10^{-5}$ and $\left(\delta^{26} \mathrm{Mg}^{*}\right)_{0}=0.6 \pm 1.0 \%$ (Fig. $\left.7 \mathrm{c}\right)$, grain 9 gave $\left({ }^{26} \mathrm{Al} /{ }^{27} \mathrm{Al}\right)_{0}=(4.9 \pm$ $0.4) \times 10^{-5}$ and $\left(\delta^{26} \mathrm{Mg}^{*}\right)_{0}=0.0 \pm 0.8 \%$ (Fig. $\left.7 \mathrm{~d}\right)$, grain 15 gave $\left({ }^{26} \mathrm{Al} /{ }^{27} \mathrm{Al}\right)_{0}=(4.8 \pm$ $0.3) \times 10^{-5}$ and $\left(\delta^{26} \mathrm{Mg}^{*}\right)_{0}=-0.6 \pm 0.6 \%$ (Fig. 7e), and grain 21 gave $\left({ }^{26} \mathrm{Al}^{27} \mathrm{Al}_{0}=(4.5\right.$ $\pm 0.2) \times 10^{-5}$ and $\left(\delta^{26} \mathrm{Mg}^{*}\right)_{0}=0.5 \pm 0.6 \%$ (Fig. 7f). Validities of these isochrons are discussed in a later section.

\subsection{Magnesium isotopic fractionations of reversely zoned melilite crystals}

Variations of mass-dependent magnesium isotopic fractionations within the reversely zoned melilite crystals along inferred directions of crystal growth are observed (Fig. 8). The fractionations range between $\sim 0 \%$ and $\sim 9 \%$ in $\delta^{25} \mathrm{Mg}$. Three patterns for magnesium isotopic fractionation are recognized. The $\delta^{25} \mathrm{Mg}$ values of grains 1 and 15 tend to decrease with increasing ${ }^{27} \mathrm{Al} /{ }^{24} \mathrm{Mg}$ ratios (Figs. 8a and 8e). Grains 3 and 21 show constant $\delta^{25} \mathrm{Mg}$ values (Figs. $8 \mathrm{~b}$ and $8 \mathrm{f}$ ). The $\delta^{25} \mathrm{Mg}$ values of grains 8 and 9 tend to increase with increasing ${ }^{27} \mathrm{Al} /{ }^{24} \mathrm{Mg}$ ratios (Figs. $8 \mathrm{c}$ and $8 \mathrm{~d}$ ).

The magnesium isotopic fractionation of grain 1 ranges from $\sim 0$ to $\sim 6 \%$ in $\delta^{25} \mathrm{Mg}$ (Fig 416 8a). The $\delta^{25} \mathrm{Mg}$ values gradually decreased with crystal growth. The ${ }^{16} \mathrm{O}$-rich zone (< 417 $\sim \AA$ Ak6) grew with a constant $\delta^{25} \mathrm{Mg}$ value of $\sim 0 \%$ (Fig. $4 \mathrm{a}$ ). 
418 Grain 15 shows magnesium isotopic fractionation ranging from $\sim 1$ to $\sim 5 \%$ in $\delta^{25} \mathrm{Mg}$ 419 (Fig. 8e). The $\delta^{25} \mathrm{Mg}$ values appear to gradually decrease with crystal growth, which is 420 similar to the case for grain 1 . The ${ }^{16} \mathrm{O}$-rich zone (< $\left.\sim \AA \mathrm{k} 6\right)$ has a constant $\delta^{25} \mathrm{Mg}$ value 421 of $\sim 1 \%$.

423 Grains 3 and 21 have uniform $\delta^{25} \mathrm{Mg}$ values of $\sim 2 \%$ and $\sim 1 \%$, respectively (Figs. $8 \mathrm{~b}$ 424 and 8f).

426 Grain 8 shows magnesium isotopic fractionation ranging from $\sim 1$ to $\sim 4 \%$ in $\delta^{25} \mathrm{Mg}$ (Fig.

427 8c). A zone with $>\sim \AA$ k 8 shows a constant $\delta^{25} \mathrm{Mg}$ value of $\sim 1 \%$, while the ${ }^{16} \mathrm{O}$-rich zone 428 (< $\AA$ A 8 ) has variable $\delta^{25} \mathrm{Mg}$ values, from $\sim 1$ to $\sim 4 \%$ according to crystal growth (Fig. $4294 \mathrm{~b})$.

431 Grain 9 shows magnesium isotopic fractionation ranging from $\sim 4$ to $\sim 9 \%$ in $\delta^{25} \mathrm{Mg}$ (Fig. 432 8d), which gradually increased with crystal growth. A zone with $>\sim \AA$ A 10 shows a 433 constant $\delta^{25} \mathrm{Mg}$ value of $\sim 4 \%$.

\section{DISCUSSION}

\subsection{Formation processes of reversely zoned melilite crystals}

439 The oxygen isotopic compositions of grains 1 and 15 changed from ${ }^{16} \mathrm{O}$-poor to ${ }^{16} \mathrm{O}$-rich 440 and the $\delta^{25} \mathrm{Mg}$ values decreased with reversely zoned crystal growths. Redistribution of 441 oxygen and magnesium within and/or among CAI minerals by solid-state diffusion in 442 the solar nebula or on the parent body has been suggested (Itoh and Yurimoto, 2003; 443 Fagan et al., 2004; Itoh et al., 2004; Ito and Messenger, 2010; Simon et al., 2011; 444 Kawasaki et al., 2015). Thus, solid-state diffusion of oxygen and magnesium isotopes in 445 reversely zoned melilite crystals should be considered as a possibility for the cause of 446 oxygen and magnesium isotopic variations. Katayama et al. (2012) showed that the 447 oxygen isotopic zoning in grain 1 is not related to the distance from the crystal rim but 448 only to crystal composition, indicating that oxygen self-diffusion in melilite was not 449 responsible for the oxygen isotopic variations in grain 1. Grain 15 showed the same 450 characteristics as grain 1. Magnesium self-diffusion in gehlenite is slower than oxygen 451 self-diffusion at temperatures below $\sim 1500 \mathrm{~K}$ (Yurimoto et al., 1989; Ito and Ganguly, 452 2009). The ambient temperature for the formation of grains 1 and 15 could also be 453 below $\sim 1500 \mathrm{~K}$, because the equilibrium condensation temperatures for grains 1 and 15 
were $\sim 1390$ to $\sim 1420 \mathrm{~K}$ at $\mathrm{P}_{\text {total }}=10^{-4}$ atm or $\sim 1470$ to $\sim 1490 \mathrm{~K}$ at $\mathrm{P}_{\text {total }}=10^{-3} \mathrm{~atm}$,

455 from a solar composition gas, according to the phase diagram of Yoneda and Grossman 456 (1995). This suggests that the magnesium isotopic variations in grains 1 and 15 cannot 457 be explained by solid-state diffusion in reversely zoned melilite crystals. The 458 well-correlated $\delta^{26} \mathrm{Mg} *$ values and ${ }^{27} \mathrm{Al} /{ }^{24} \mathrm{Mg}$ ratios of grains 1 and 15 (Figs. 7a and 7e) 459 were also inconsistent with the redistribution of magnesium isotopes after the 460 solidification. Therefore, these grains likely preserve their original magnesium isotopic fractionation patterns obtained during crystal growths.

MacPherson and Grossman (1984) showed that the occurrence of reversely zoned melilite crystals found in fluffy Type A CAIs could be explained by condensation from a solar nebular gas during a period of decreasing pressure. This condensation can also explain the reversely zoned melilite crystals in V2-01 fluffy Type A CAI (Katayama et al., 2012). In contrast, Grossman et al. (2002) suggested that the reversely zoned melilite crystals could also be formed by crystallization from incomplete melts with melt evaporation. They predicted that the magnesium isotopes of reversely zoned melilite formed by such a process would have significantly enriched $\delta^{25} \mathrm{Mg}$ at the gehlenitic side of the crystal. However, grains 1 and 15 showed depleted $\delta^{25} \mathrm{Mg}$ at the gehlenitic side of the crystal (Figs $8 \mathrm{a}$ and 8e), which is inconsistent with the above-mentioned prediction. Therefore, the magnesium isotopic fractionation patterns in grains 1 and 15 are strong evidence for a condensation origin of the reversely zoned melilite crystals, as proposed by Katayama et al. (2012).

The magnesium isotopic variations in grains 1 and 15 may represent responses to changes in magnesium isotopic compositions of the surrounding nebular gas from which the grains were condensed. At this time, the pressure of surrounding nebular gas may have decreased during condensation (MacPherson and Grossman, 1984). In summary, the oxygen isotopic compositions of the surrounding nebular gas changed from ${ }^{16} \mathrm{O}$-poor to ${ }^{16} \mathrm{O}$-rich, the $\delta^{25} \mathrm{Mg}$ values decreased, and the pressure decreased, 483 during the condensation of grains 1 and 15 . The ${ }^{16} \mathrm{O}$-rich gehlenitic zone of grain 1 484 showed a homogeneous $\delta^{25} \mathrm{Mg}$ of $\sim 0 \%$ (Fig. 4a), indicating that the ${ }^{16} \mathrm{O}$-rich nebular gaseous reservoir had nearly solar $\delta^{25} \mathrm{Mg}$ value. The magnesium isotopic variations Type A CAI originated from a solar coronal gas (Katayama et al., 2012).

\subsubsection{Grains with constant $\delta^{25} \mathrm{Mg}$ values}


490 Grains 3 and 21 showed constant $\delta^{25} \mathrm{Mg}$ values of $\sim 2 \%$ and $\sim 1 \%$, respectively (Figs. $8 \mathrm{~b}$ and $8 \mathrm{f}$ ). Because there were no significant enrichments of $\delta^{25} \mathrm{Mg}$ at the gehlenitic zone of the crystal, the formation of grains 1 and 15 by crystallization from incomplete melts with melt evaporation is unlikely, but formation by condensation from the solar nebular gas is possible. It is noted that we cannot prove a condensation origin of grains 3 and 21, because a significant magnesium isotopic fractionation is not always necessary during melt evaporation processes, as will be discussed in Section 4.1.3.

The oxygen isotopic compositions of grain 3 are homogeneously ${ }^{16} \mathrm{O}$-poor $\left(\Delta^{17} \mathrm{O} \sim\right.$ $-5 \%$ ), while those of grain 21 show variations ranging from $\Delta^{17} \mathrm{O} \sim-8$ to $-20 \%$ and changing from ${ }^{16} \mathrm{O}$-poor to ${ }^{16} \mathrm{O}$-rich with crystal growth. Given that grains 3 and 21 formed by condensation from nebular gas, the oxygen and magnesium isotopic variations suggest that grain 3 formed in a homogeneous, ${ }^{16} \mathrm{O}$-poor, nebular gaseous reservoir with a nearly solar $\delta^{25} \mathrm{Mg}$ value, while grain 21 formed in a nebular gas that changed from ${ }^{16} \mathrm{O}$-poor to ${ }^{16} \mathrm{O}$-rich, with nearly solar $\delta^{25} \mathrm{Mg}$ value.

\subsubsection{Grains in which $\delta^{25} \mathrm{Mg}$ values increase with crystal growth} $8 \mathrm{~d}$ ). The trends of magnesium isotopic fractionations observed in these grains are consistent with the formation of reversely zoned melilite crystals by crystallization from evaporating melts (Grossman et al., 2002). Melt evaporation causes loss of magnesium and silicon relative to more refractory aluminum and calcium, and results in heavier magnesium and silicon isotopic compositions for the residual melt than for the precursor (e.g., Richter et al., 2002). Laboratory evaporation experiments show that the isotopic fractionation of evaporating melts follows the Rayleigh law (Richter et al., 2007; Mendybaev et al., 2013). The equation is given as $R / R_{0}=f^{(\alpha-1)}$, where $R$ is ${ }^{2} \mathrm{Mg} /{ }^{24} \mathrm{Mg}$ in the residual melt, $R_{0}$ is ${ }^{25} \mathrm{Mg} /{ }^{24} \mathrm{Mg}$ in the melt before evaporation, $f$ is the 517 fraction of ${ }^{24} \mathrm{Mg}$ remaining in the residual melt, and $\alpha$ is the kinetic isotopic 518 fractionation factor. Richter et al. (2007) determined the kinetic isotopic fractionation 519 factor, $\alpha$, for magnesium from a CAI-composition melt in vacuum at various 520 temperature conditions. The relationship between the magnesium isotopic fractionation 521 and the fraction of ${ }^{24} \mathrm{Mg}$ remaining in the residual melt at a given temperature can be calculated.

524 The chemical compositions of grains 8 and 9 are in the range Åk5-20. According to the 
526 would be higher than $\sim 1750 \mathrm{~K}$ and lower than $\sim 1830 \mathrm{~K}$, because these are the solidus 527 temperatures of $\AA \mathrm{k} 20$ and $\AA \mathrm{k} 5$, respectively. We used the kinetic isotopic fractionation 528 factor of $\alpha=0.98822$ at $1873 \mathrm{~K}$ (Richter et al., 2007), which was the lowest temperature 529 in their experiment. Because the observed magnesium isotopic fractionation for grains 8 530 and 9 were $\sim 3 \%$ and $\sim 5 \%$, respectively, in $\delta^{25} \mathrm{Mg}$, (Figs $8 \mathrm{c}$ and $8 \mathrm{~d}$ ), the fraction of

$531{ }^{24} \mathrm{Mg}$ remaining in the residual evaporating melt could be calculated using the kinetic 532 isotope fractionation factor of $\alpha=0.98822$. The fractions of ${ }^{24} \mathrm{Mg}$ remaining in the 533 residual melt for grains 8 and 9 were calculated to be $\sim 78 \%$ and $\sim 65 \%$, respectively (Fig. 534 9).

536 Richter et al. (2007) found a slight temperature dependence for the kinetic isotopic 537 fractionation factor. An extrapolation from their data gave a kinetic isotopic 538 fractionation factor of $\alpha \sim 0.9898$ at $1750 \mathrm{~K}$, which is the lower limit of melting 539 temperature for grains 8 and 9. If use consider this kinetic isotopic fractionation factor, 540 the fractions of ${ }^{24} \mathrm{Mg}$ remaining in the residual melt for grains 8 and 9 would be $\sim 75 \%$ 541 and $\sim 61 \%$, respectively (Fig. 9). The difference of temperature between $1873 \mathrm{~K}$ and $5421750 \mathrm{~K}$ corresponds to the difference of $f=4 \%$, which is negligible for the discussion 543 here. Thus, we used $\alpha=0.98822$.

545 The residual melt composition of $f=78 \%$ with $\sim 3 \%$ of mass-dependent isotope 546 fractionation in $\delta^{25} \mathrm{Mg}$ for grain 8 corresponds to ${ }^{27} \mathrm{Al} /{ }^{24} \mathrm{Mg} \sim 40$ (Figs. 8c). The residual 547 melt composition of $f=65 \%$ with $\sim 5 \%$ of mass dependent isotope fractionation in $548 \delta^{25} \mathrm{Mg}$ for grain 9 corresponds to ${ }^{27} \mathrm{Al} /{ }^{24} \mathrm{Mg} \sim 44$ (Figs. 8d). Therefore, the melt 549 composition before evaporation would be calculated to be ${ }^{27} \mathrm{Al} /{ }^{24} \mathrm{Mg} \sim 31$ for grain 8 550 and ${ }^{27} \mathrm{Al} /{ }^{24} \mathrm{Mg} \sim 29$ for grain 9 . For grain 8 , the ${ }^{27} \mathrm{Al} /{ }^{24} \mathrm{Mg}$ ratio of $\sim 31$ corresponds to 551 the boundary between ${ }^{16} \mathrm{O}$-poor and ${ }^{16} \mathrm{O}$-rich zones, where the $\delta^{25} \mathrm{Mg}$ value increases 552 (Fig. 4b), which apparently supports crystallization from incomplete melts with 553 simultaneous evaporation. This formation process, however, is not in agreement with 554 the result that grain 8 already had reverse zoning before evaporative melting. Because 555 this process involves the incomplete melting of pre-existing melilite, with melt 556 evaporation and subsequent overgrowth of melilite with reverse zoning on the relict 557 core, a preferential melting of relatively gehlenitic rim of reversely zoned pre-existing 558 melilite crystal is necessary. However, the liquidus temperature is lower in the interior, 559 åkermanitic zone than in the outer, gehlenitic zone of reversely zoned grain 8 (Osborn 560 and Schairar, 1941). The melting relationship implies that it is difficult for the interior 561 zone to be unmelted at the melting temperature of the outer zone of grain 8 . Therefore, 
562 the melt evaporation process is not possible for the formation of reverse zoning in grain 563 8. On the other hand, the ${ }^{27} \mathrm{Al} /{ }^{24} \mathrm{Mg}$ of the melt before evaporation was calculated to be $564 \sim 29$ for grain 9, corresponding to $\delta^{25} \mathrm{Mg} \sim 6 \%$ (Fig. 8d). However, according to the 565 calculation, the $\delta^{25} \mathrm{Mg}$ at ${ }^{27} \mathrm{Al} /{ }^{24} \mathrm{Mg} \sim 29$ should be 5\% lower than $\delta^{25} \mathrm{Mg} \sim 9 \%$ at

$566{ }^{27} \mathrm{Al} /{ }^{24} \mathrm{Mg} \sim 44$, while the observed difference of $\delta^{25} \mathrm{Mg}$ was $\sim 3 \%$. These disagreements 567 between observations and calculations suggest that the melt evaporation process did not 568 play a main role in the formation of reverse zoning for grains 8 and 9.

570 It is noted that the kinetic isotopic fractionation factor, $\alpha$, depends on the chemical 571 composition of the starting melt (Mendybaev et al. 2013). In evaporation experiments 572 by Richter et al. (2007), the starting composition had 11 wt \% MgO, although 573 reversely zoned melilite crystals in fluffy Type A CAIs have $\mathrm{MgO}<5 \mathrm{wt} \%$. However, 574 there are no evaporation experiments using the chemical composition of melilite, which 575 is necessary to accurately discuss the formation processes of reversely zoned melilite 576 crystals.

578 We assumed Rayleigh fractionation for the discussion of the formation of reversely 579 zoned melilite crystals, but isotope exchange between evaporated species and the melt 580 should also be taken into account. Evaporation with back reaction of evaporated species 581 can reduce net isotopic fractionation, and as a result, elemental fractionation can be 582 decoupled from isotopic fractionation (Ozawa and Nagahara, 2001). In fact, chondrules 583 lack the isotopic fractionation of evaporated elements predicted by Rayleigh 584 fractionation (e.g., Alexander et al., 2000; Galy et al., 2000). Given that the kinetic 585 isotopic fractionation of magnesium during evaporation is decreased by isotope 586 exchange, the ${ }^{27} \mathrm{Al} /{ }^{24} \mathrm{Mg}$ for melts before evaporation could be lower. Therefore, the 587 formation of reversely zoned grains 8 and 9 could possibly be explained by the 588 crystallization from evaporating melts depending on evaporation conditions.

590 In contrast to the formation of reversely zoned melilite crystals by melt evaporation, 591 condensation from a solar nebular gas during a period of decreasing pressure 592 (MacPherson and Grossman, 1984) can readily explain their formation, similar to other 593 reversely zoned grains (1, 3, 15, and 21 discussed in Sections 4.1.1 and 4.1.2). 594 Considering a consistency with other grains, the condensation formation of grains 8 and 5959 appear to be highly plausible. If these grains formed by condensation from solar 596 nebular gas, it is implied that the oxygen isotopic compositions of the surrounding 597 nebular gas changed from ${ }^{16} \mathrm{O}$-poor to ${ }^{16} \mathrm{O}$-rich and the $\delta^{25} \mathrm{Mg}$ values increased as 
condensation progressed. environment for fluffy Type A CAI V2-01

The spinel crystals in the CAI interior were enclosed by melilite crystals. This relationship clearly shows that the spinel was formed prior to the melilite. In contrast, thermodynamic calculations predict condensation of melilite from the solar nebular gas before spinel (e.g., Grossman et al., 1972; Wood and Hashimoto, 1993). Spinel-hibonite aggregates in CM2 chondrites show textural evidence for direct condensation of spinel after hibonite (MacPherson et al., 1984), which has been supported by additional multiple evidences of textures and isotopic and trace elemental compositions (MacPherson and Davis, 1994; Simon et al., 2006). In addition, Han et al. (2015) conducted crystallographic observations of the spinel-hibonite inclusions in the ALH77037 CO3 chondrite, showing epitaxial nucleation and growth of spinel on hibonite. These studies suggest that hibonite reacted with gas to form spinel and melilite condensation could be kinetically hindered relative to spinel. In this model, spinel could be formed before melilite. Spinel-hibonite-perovskite assemblages, of which spinel replaces hibonite, were also observed in melilite-rich region of a Type A CAI from the Allende CV3 chondrite (Park et al., 2012). On the other hand, the formation of spinel and melilite in distinct reservoirs could be considered because of the different oxygen isotopic compositions of spinel and melilite. Given that the condensation of melilite occurred in a distinct reservoir from the one in which spinel formed, the formation of spinel prior to the melilite can readily be explained.

Katayama et al. (2012) suggested that the reversely zoned melilite crystals formed at the inner edge region of the solar nebula, where coronal and nebular gases are encountered and mixed (Yurimoto et al., 2008). In this case, the mixing of coronal gas with nebular gas may result in a change in chemical composition of the nebular gas, which implies that the condensation of melilite occurred in a gaseous reservoir different from that of spinel formation. Thus, the formation sequence may not necessarily follow the predicted equilibrium condensation sequence in a closed system. In V2-01, spinel in the interior and the melilite crystals have distinct $\left({ }^{26} \mathrm{Al} /{ }^{27} \mathrm{Al}\right)_{0}$ values, as discussed in Section 4.3.5.

631 by single heating event. Therefore, the observed textural relationship between the spinel

632 in the CAI interior and the melilite crystals in V2-01 can be understood by the 633 formation of spinel prior to melilite. The fassaite grains in CAI interior enclosed by 
634 melilite crystals were also likely formed prior to the melilite crystals as shown by the 635 textural relationships. Oxygen self-diffusion in spinel and that in clinopyroxene are 636 much slower than oxygen self-diffusion in melilite at temperatures below $\sim 1500 \mathrm{~K}$ 637 (Yurimoto et al., 1989; Ryerson and McKeegan, 1994), which suggests that the oxygen 638 isotopic compositions of spinel and fassaite in V2-01 represent the original 639 compositions at their formation. Thus, the spinel in the CAI interior formed in an $640{ }^{16}$ O-rich reservoir in the solar nebula, as indicated by its ${ }^{16} \mathrm{O}$-rich composition (Fig. 5). 641 On the other hand, the variations of oxygen isotopic compositions for fassaite grains 642 (Fig. 5) suggest that they formed in a variable oxygen isotope reservoir. These imply 643 that the oxygen isotopic compositions of nebular gas for fluffy Type A CAI formation 644 were already variable before melilite formation.

646 The reversely zoned melilite grains 1 and 15 have variations in $\delta^{25} \mathrm{Mg}$, where the $\delta^{25} \mathrm{Mg}$ 647 values decrease with decreasing åkermanite content, while the $\delta^{25} \mathrm{Mg}$ values increase 648 with decreasing åkermanite content in the grains 8 and 9 (Fig. 8). In contrast, the $\delta^{25} \mathrm{Mg}$ 649 values for grains 3 and 21 are constant despite variations in åkermanite content (Figs. 8b 650 and $8 \mathrm{f}$ ). The observed variations of magnesium isotopic fractionations in the reversely 651 zoned melilite crystals indicate the presence of variable magnesium isotope gaseous 652 reservoirs in the fluffy Type A CAI-forming region of the solar nebula. These melilite 653 grains had grown individually in distinct environments of the solar nebula, and 654 subsequently accumulated into the CAI. A Type A CAI from the Efremovka CV3, HKE 65501 , is composed of two domains, which grew in nebular reservoirs with distinct oxygen 656 isotopic compositions, temperature and/or pressure (Kawasaki et al., 2012). Therefore, 657 crystals or domains forming separately in the solar nebula and then accumulating to 658 form each CAI may be common in the formation of fluffy Type A CAI.

660 The formation process of the W-L rims on coarse-grained CAIs remains controversial. 661 There are two major models describing W-L rim formation: as subsolidus evaporation 662 residues (Wark, 2005); and condensation products (Simon et al., 2005). It was revealed 663 that the W-L rims on Types A and B CAIs are enriched in rare earth elements (REEs) 664 relative to the underlying CAI interiors (Wark and Boynton, 2001; Wark, 2005). 665 Differences in the chondrite-normalized REE patterns between the $\mathrm{W}-\mathrm{L}$ rims and the 666 host CAIs could be explained by the evaporation of host CAI interiors to form the W-L 667 rims. Wark and Boynton (2001) suggested that the W-L rims formed by flash heating at 668 a high temperature ( $3000 \mathrm{~K}$ for a few seconds), although Wark (2005) excluded flash 669 heating, based on observations of melilite adjacent to the W-L rim of a fluffy Type A 
670 CAI from Allende, which showed no sign of melting. Alternatively, subsolidus 671 evaporation was suggested as the formation process of W-L rims (Wark, 2005). In 672 contrast, Simon et al. (2005) suggested a condensation origin for W-L rims. They 673 examined magnesium isotopic compositions of both W-L rims and melilite in the CAI 674 interior, and showed that the W-L rims have a constant $\delta^{25} \mathrm{Mg}$ of $\sim 0$ while adjacent 675 melilites have variable $\delta^{25} \mathrm{Mg}$ values in each CAI. These relationships suggest that the 676 W-L rims are not the derivatives of the CAI interiors but are condensation products 677 (Simon et al., 2005). Although not all the W-L rims on all CAIs might have formed 678 through the same process, the W-L rims at least would have formed at the last stages of 679 each CAI formation. Therefore, after the condensation of ${ }^{16} \mathrm{O}$-rich melilite, formation of 680 the V2-01 W-L rim might have occurred continuously in an ${ }^{16} \mathrm{O}$-rich reservoir in the 681 solar nebula, as suggested by its ${ }^{16} \mathrm{O}$-rich compositions (Fig. 5).

683 The formation sequence and oxygen isotope change in the surrounding environment of 684 the V2-01 fluffy Type A CAI can be summarized as follows (Fig. 10): (1) The spinel 685 crystals formed in an ${ }^{16} \mathrm{O}$-rich reservoir $\left(\Delta^{17} \mathrm{O} \sim-24 \%\right.$ ), while the fassaite crystals 686 formed in a variable oxygen isotope reservoir $\left(\Delta^{17} \mathrm{O} \sim-12\right.$ and $-17 \%$ o). (2) The 687 reversely zoned melilite crystals started to form in various ${ }^{16} \mathrm{O}$-poor nebular gaseous 688 reservoirs $\left(\Delta^{17} \mathrm{O}\right.$ values larger than $-10 \%$ ) with variable magnesium isotopic 689 compositions. A portion of melilite crystals enclosed the spinel and fassaite crystals 690 formed during stage (1). The melilite crystals were overgrown in a variable oxygen 691 isotope reservoir changing from ${ }^{16} \mathrm{O}$-poor to ${ }^{16} \mathrm{O}$-rich $\left(\Delta^{17} \mathrm{O} \sim-25 \%\right)$. (3) The melilite 692 crystals accumulated to form the V2-01 CAI precursor. (4) W-L rim minerals were 693 formed in an ${ }^{16} \mathrm{O}$-rich reservoir $\left(\Delta^{17} \mathrm{O} \sim-23 \%\right)$. The formation sequence above 694 indicates that the V2-01 CAI was formed in variable oxygen isotope reservoirs that 695 changed from ${ }^{16} \mathrm{O}$-rich to ${ }^{16} \mathrm{O}$-poor and back to ${ }^{16} \mathrm{O}$-rich. The trend of cyclic oxygen 696 isotope change in the surrounding environment is also suggested on the basis of oxygen 697 isotope distributions in other CAIs, including a Type B2 CAI from Vigarano and 698 compact Type A CAIs from the Allende CV3 (Yoshitake et al., 2005; Simon et al., 2011; 699 Park et al., 2012).

700

$701 \quad 4.3$ Formation period of the V2-01 fluffy Type A CAI

\section{$702 \quad 4.3 .1 \mathrm{Al}-\mathrm{Mg}$ systematics of spinel in the CAI interior}

703 Spinel in the CAI interior probably formed before the start of melilite condensation, as 704 discussed in Section 4.2, suggesting that the formation age of the spinel should be 705 estimated independently from other constituent minerals of V2-01. The spinel showed a 
706 constant $\delta^{26} \mathrm{Mg}^{*}$ value of $\sim 0.98 \%$ (Fig. 6). Given that we defined the isochron of the 707 spinel in the CAI interior assuming an initial $\left(\delta^{26} \mathrm{Mg} *\right)_{0}$ of $-0.0159 \pm 0.0014 \%$ or the 708 Solar System (Larsen et al., 2011), the initial value of the spinel was $\left({ }^{26} \mathrm{Al} /{ }^{27} \mathrm{Al}\right)_{0}=(5.6$ $709 \pm 0.2) \times 10^{-5}$. On the other hand, using the initial $\left(\delta^{26} \mathrm{Mg}^{*}\right)_{0}$ value of $-0.040 \pm 0.029 \%$, 710 obtained in a different laboratory (Jacobsen et al., 2008), gave $\left({ }^{26} \mathrm{Al} /{ }^{27} \mathrm{Al}\right)_{0}=(5.7 \pm 0.3)$ $711 \times 10^{-5}$, which is indistinguishable from our value because of our measurement errors of 712 the $\delta^{26} \mathrm{Mg}^{*}$. Therefore, the selection of initial values was not a significant issue for our $713{ }^{26} \mathrm{Al}-{ }^{26} \mathrm{Mg}$ chronological study.

714

715 The inferred initial value of $\left({ }^{26} \mathrm{Al} /{ }^{27} \mathrm{Al}\right)_{0}=(5.6 \pm 0.2) \times 10^{-5}$ might be slightly larger 716 than the canonical $\left({ }^{26} \mathrm{Al} /{ }^{27} \mathrm{Al}\right)_{0}$ value of $(5.23 \pm 0.13) \times 10^{-5}$ (Jacobsen et al., 2008) or $717(5.252 \pm 0.019) \times 10^{-5}$ (Larsen et al., 2011), although they are within 3 sigma errors of 718 each other. The initial value of the interior spinel may have been disturbed through 719 melting events or solid-state diffusion during late thermal events, resulting in 720 magnesium isotope exchange with surrounding minerals. In order for the ${ }^{26} \mathrm{Mg} *$ of 721 spinel to have been disturbed by resetting due to either the melting event or the 722 solid-state diffusion, surrounding minerals should have different ${ }^{27} \mathrm{Al} /{ }^{24} \mathrm{Mg}$ ratios than 723 the spinel $\left({ }^{27} \mathrm{Al} /{ }^{24} \mathrm{Mg} \sim 2.5\right)$. Melilite in $\mathrm{V} 2-01$ showed an ${ }^{27} \mathrm{Al} /{ }^{24} \mathrm{Mg}$ ratio of at least $\sim 10$ 724 (Fig. 7), which meets this requirement. However, the spinel is a liquidus mineral in the 725 bulk composition of the V2-01 fluffy Type A CAI (Stolper, 1982), indicating that a 726 complete melting of the CAI is required for complete resetting of the $\mathrm{Al}-\mathrm{Mg}$ system. 727 Because the V2-01 CAI has never been extensively melted, the resetting of $\mathrm{Al}-\mathrm{Mg}$ 728 system due to melting event is implausible.

729

730 Another possibility is the resetting of the $\mathrm{Al}-\mathrm{Mg}$ system due to magnesium isotope 731 exchange between the spinel and the surrounding melilite by solid-state diffusion of 732 magnesium isotopes during metamorphism in the asteroidal parent body of the Vigarano 733 meteorite. Magnesium isotope exchange between spinel and anorthite resulting in 734 resetting of the $\mathrm{Al}-\mathrm{Mg}$ system was demonstrated in a Type C CAI from Allende, 735 although it depended on the grain sizes (Kawasaki et al., 2015). The observed $\mathrm{Mg}-\mathrm{Fe}$ 736 zoning in the W-L rim spinel, with sizes of $\sim 3 \mu \mathrm{m}$ (Fig. 2c), suggests that the diffusion 737 distance of $\mathrm{Fe}^{2+}$ in the spinel in V2-01 was less than a few micrometers. An 738 incorporation of $\mathrm{Fe}^{2+}$ might have occurred during the metamorphism. Diffusivity of 739 magnesium isotopes in spinel is almost the same as or slower than $\mathrm{Fe}^{2+}$ (Liermann and 740 Ganguly, 2002), indicating that the diffusion distance of magnesium isotopes in the 741 spinel in V2-01 should have been less than a few micrometers. This further suggests that 
742 the exchange of magnesium isotopes by solid-state diffusion during metamorphism was

743 probably insufficient to disturb the ${ }^{26} \mathrm{Mg}^{*}$ of spinel in the CAI interior, which have sizes 744 of a few tens of micrometers, that were measured for ${ }^{26} \mathrm{Al}-{ }^{26} \mathrm{Mg}$ systematics. Therefore, 745 the resetting of the $\mathrm{Al}-\mathrm{Mg}$ system to disturb the ${ }^{26} \mathrm{Mg}$ * for the spinel in the CAI interior 746 probably did not occur, and the spinel might preserve a closed system from its 747 formation.

\subsubsection{Al-Mg systematics of the diopside and spinel in $\mathrm{W}-\mathrm{L}$ rim}

750 The $\mathrm{Al}-\mathrm{Mg}$ isotopic compositions of diopside and spinel in the $\mathrm{W}-\mathrm{L}$ rim were measured 751 and a mineral isochron for the W-L rim could be defined (Fig. 6). The initial values 752 inferred for the isochron of W-L rim were $\left({ }^{26} \mathrm{Al} /{ }^{27} \mathrm{Al}\right)_{0}=(4.5 \pm 0.4) \times 10^{-5}$ and $753\left(\delta^{26} \mathrm{Mg} *\right)_{0}=-0.05 \pm 0.05 \%$. The $\left({ }^{26} \mathrm{Al} /{ }^{27} \mathrm{Al}\right)_{0}$ value is significantly lower than that of 754 the spinel in the CAI interior or the canonical initial value, which is mainly due to the 755 low $\delta^{26} \mathrm{Mg}^{*}$ value for spinel in the W-L rim $(\sim 0.79 \%$ o). For a chronological 756 interpretation of the deviation of $\left({ }^{26} \mathrm{Al} /{ }^{27} \mathrm{Al}\right)_{0}$ values, studying the exchange of the 757 magnesium isotope with the surrounding minerals by solid-state diffusion was also 758 considered important. For a decrease in the concentration of ${ }^{26} \mathrm{Mg}^{*}$ in the W-L rim 759 spinel through the exchange of magnesium isotope with other minerals, the presence of 760 adjacent minerals having lower ${ }^{27} \mathrm{Al} /{ }^{24} \mathrm{Mg}$ ratios than that in the spinel $\left({ }^{27} \mathrm{Al} /{ }^{24} \mathrm{Mg} \sim 2.5\right)$ 761 is necessary. However, the mineral adjacent to the spinel, i.e., melilite, has an ${ }^{27} \mathrm{Al} /{ }^{24} \mathrm{Mg}$ 762 ratio of $>20$, suggesting that exchange of the magnesium isotope with other minerals by 763 solid-state diffusion to be unlikely. The possibility of the exchange of the magnesium 764 isotope with the Vigarano matrix minerals should also be cared, however, the exchange 765 could be disregarded since, based on the discussion in Section 4.3.1, the distance of 766 diffusion of the magnesium isotope in the V2-01 spinel was estimated to be less than a 767 few micrometers. Therefore, the spinel in the W-L rim may have preserved a closed 768 system starting from its formation and the inferred $\left({ }^{26} \mathrm{Al} /{ }^{27} \mathrm{Al}\right)_{0}$ value has a 769 chronological significance.

770

\subsection{3 $\mathrm{Al}-\mathrm{Mg}$ systematics of the reversely zoned melilite crystals}

772 As discussed in Sections 4.1.1 and 4.1.2, the grains 1, 3, 15 and 21 likely formed by 773 condensation from solar nebular gas. If the crystal growth of these grains was slow 774 enough, the gehlenitic sides would have depleted $\delta^{26} \mathrm{Mg} *$ relative to the isochron lines 775 in the ${ }^{26} \mathrm{Al}-{ }^{26} \mathrm{Mg}$ isochron diagrams, owing to the evolution of the $\mathrm{Al}-\mathrm{Mg}$ system of 776 solar nebular gas. However, the data show that $\delta^{26} \mathrm{Mg}^{*}$ of the gehlenitic sides of these 777 grains are not systematically depleted relative to the isochron slopes (Fig. 7), which 
778 indicates that they formed in the gas with a homogeneous distribution of $\left({ }^{26} \mathrm{Al} /{ }^{27} \mathrm{Al}\right)_{0}$ 779 within the time durations corresponding to the errors of $\left({ }^{26} \mathrm{Al} /{ }^{27} \mathrm{Al}\right)_{0}$ value for each 780 isochron although the oxygen isotopic compositions in the gas were variable. The time 781 durations for the formation of the grains were estimated to be within 0.15 Myr for grain 782 1, $0.27 \mathrm{Myr}$ for grain 3, $0.12 \mathrm{Myr}$ for grain 15, and $0.09 \mathrm{Myr}$ for grain 21. The 783 condensation of the reversely zoned melilite crystals (grains 1, 3, 15 and 21) from solar nebular gas occurred within the time duration of 0.09-0.27 Myr.

786 As discussed in Section 4.1.3, grains 8 and 9 could have been formed by either the crystallization from the evaporating melt with a back reaction of the evaporated species or the condensation from the solar nebular gas. Given that these grains formed by crystallization from evaporating melt, the $\left({ }^{26} \mathrm{Al} /{ }^{27} \mathrm{Al}\right)_{0}$ values for the overgrown melilite 790 from the evaporating melt and for the relic melilite may be distinct. However, according to our data, grains 8 and 9 seem to have well-resolved single isochrons, implying their formations to have included evaporative melting that occurred within time durations of

$793 \quad 0.20 \mathrm{Myr}$ for grain 8 and 0.15 Myr for grain 9. On the other hand, if they were formed 794 by condensation, the time durations for the condensation were calculated to be $0.20 \mathrm{Myr}$ 795 for grain 8 and 0.15 Myr for grain 9 using the same method described for grains 1, 3, 15, 796 and 21.

798 The $\left({ }^{26} \mathrm{Al} /{ }^{27} \mathrm{Al}\right)_{0}$ values for the reversely zoned melilite crystals in V2-01 were smaller 799 than the canonical $\left({ }^{26} \mathrm{Al} /{ }^{27} \mathrm{Al}\right)_{0}$ value (Jacobsen et al., 2008; Larsen et al., 2011) (Fig. 11). 800 A possible explanation for this discrepancy might be the systematic shift in the $801\left({ }^{26} \mathrm{Al} /{ }^{27} \mathrm{Al}\right)_{0}$ values resulting from the analytical artifacts for the determination of the $802{ }^{27} \mathrm{Al} /{ }^{24} \mathrm{Mg}$ ratio. We used synthetic melilite glass with ${ }^{27} \mathrm{Al} /{ }^{24} \mathrm{Mg}=3.82$ as the standard 803 in terms of the relative sensitivity factor (RSF) for aluminium and magnesium. If the 804 RSF was shifted by $\sim 11 \%$, the discrepancy of $\left({ }^{26} \mathrm{Al} /{ }^{27} \mathrm{Al}\right)_{0}$ value observed in this study 805 can be accounted for. However, we measured the ${ }^{27} \mathrm{Al} /{ }^{24} \mathrm{Mg}$ ratios of the melilite using 806 FE-SEM equipped with EDS to confirm the ${ }^{27} \mathrm{Al} /{ }^{24} \mathrm{Mg}$ ratios determined by the SIMS 807 measurements; and as a result of which, a systematic shift of the level of $\sim 11 \%$ in the $808{ }^{27} \mathrm{Al} /{ }^{24} \mathrm{Mg}$ ratios was never observed, suggesting that the discrepancy between the $809\left({ }^{26} \mathrm{Al} /{ }^{27} \mathrm{Al}\right)_{0}$ values for the melilite and the canonical $\left({ }^{26} \mathrm{Al} /{ }^{27} \mathrm{Al}\right)_{0}$ value would not have 810 resulted from the analytical artifacts for the determination of the ${ }^{27} \mathrm{Al} /{ }^{24} \mathrm{Mg}$ ratio. The 811 well-correlated isochrons among the wide range of ${ }^{27} \mathrm{Al} /{ }^{24} \mathrm{Mg}$ ratios (Fig. 7) support this 812 inference. Therefore, it can be said that the inferred $\left({ }^{26} \mathrm{Al} /{ }^{27} \mathrm{Al}\right)_{0}$ values for the melilite 813 have chronological significance. 


\section{$815 \quad$ 4.3.4 Al-Mg systematics of the fassaite enclosed by melilite}

816 If we draw a regression line for the $\mathrm{Al}-\mathrm{Mg}$ isotopic compositions for fassaite, the line 817 seems to give values of $\left({ }^{26} \mathrm{Al} /{ }^{27} \mathrm{Al}\right)_{0}=(5.1 \pm 1.8) \times 10^{-5}$ and $\left(\delta^{26} \mathrm{Mg} *\right)_{0}=0.1 \pm 0.4 \%$.

818 However, two problems were encountered while defining the fassaite isochron: (1) the 819 oxygen isotopic compositions for fassaite were variable (Fig. 5); and (2) the regression 820 would essentially be based on two points. The variable oxygen isotopic compositions of 821 the fassaite grains argue against the possibility of them being formed from a single 822 reservoir. On the other hand, the ${ }^{26} \mathrm{Al}^{-26} \mathrm{Mg}$ isochron should be defined for minerals that 823 formed from a single reservoir under equilibrium (e.g., Kawasaki et al., 2015). Thus, the 824 isochron for fassaite cannot be defined readily. However, in spite of their variable 825 oxygen isotopic compositions, we defined the isochrons for the reversely zoned melilite 826 crystals in Section 4.3.3. The isochrons of the reversely zoned melilite crystals could be 827 tested by using data with various ${ }^{27} \mathrm{Al} /{ }^{24} \mathrm{Mg}$ ratios, and as a result, no systematic shifts 828 in the data plots were observed. However, in the case of fassaite, the regression line was 829 drawn basically using two points; thus, any systematic shifts in the data plots could not 830 be determined. Therefore, the fassaite isochron has not been provided in this paper. 831 Nevertheless, the $\mathrm{Al}-\mathrm{Mg}$ isotopic compositions for the fassaite grains seem to plot on 832 the model isochron for the spinel in the CAI interior and not on the mineral isochron of 833 the W-L rim (Fig. 6), implying that the fassaite grains formed simultaneously with the 834 spinel in the CAI interior before the formation of the W-L rim, which is in agreement 835 with the formation sequences estimated through the petrographic observations.

\subsubsection{Formation period of the V2-01 fluffy Type A CAI}

838 The $\left({ }^{26} \mathrm{Al} /{ }^{27} \mathrm{Al}\right)_{0}$ values are identical among the six reversely zoned melilite crystals and 839 the W-L rim within the analytical errors (Fig. 11), and show an average value of (4.7 \pm $8400.3) \times 10^{-5}(2 \mathrm{SD})$. The time duration for their formation was calculated to be within 8410.13 Myr. Thus, it can be inferred that the formation and accumulation of the reversely 842 zoned melilite crystals and the formation of the W-L rim occurred over a period of less 843 than $0.13 \mathrm{Myr}$ in the variable oxygen isotope gaseous reservoir that changed from $844{ }^{16} \mathrm{O}$-poor to ${ }^{16} \mathrm{O}$-rich (Fig. 10). On the other hand, the spinel in CAI interior shows $845\left({ }^{26} \mathrm{Al} /{ }^{27} \mathrm{Al}\right)_{0}$ value of $(5.6 \pm 0.2) \times 10^{-5}$, which is larger than the value of $(4.7 \pm 0.3) \times$ $84610^{-5}$ for the melilite crystals and the W-L rim (Fig. 11). The difference in the $\left({ }^{26} \mathrm{Al} /{ }^{27} \mathrm{Al}\right)_{0}$ 847 values corresponds to an age difference of $0.18 \pm 0.07 \mathrm{Myr}$, indicating that the V2-01 848 fluffy Type A CAI formed over a period of $0.18 \pm 0.07 \mathrm{Myr}$ in oxygen isotope reservoirs 849 that varied from ${ }^{16} \mathrm{O}$-rich to ${ }^{16} \mathrm{O}$-poor and back to ${ }^{16} \mathrm{O}$-rich (Fig. 10). 


\section{$851 \quad 4.4$ Implications for astrophysical setting of Type A CAI-forming region}

852 Katayama et al. (2012) proposed that the change in the oxygen isotopic composition of 853 the surrounding nebular gas from ${ }^{16} \mathrm{O}$-poor to ${ }^{16} \mathrm{O}$-rich during the growth of the 854 reversely zoned melilite crystals in the V2-01 fluffy Type A CAI corresponds to the 855 inner edge region of the solar nebula, where ${ }^{16} \mathrm{O}$-rich solar and ${ }^{16} \mathrm{O}$-poor planetary gases 856 are encountered and mixed (Yurimoto et al., 2008). The environmental change around 857 the melilite crystals might have occurred due to radial excursion of inner edge of solar 858 protoplanetary disk (Shu et al., 1997; Itoh and Yurimoto, 2003) or the radial 859 transportation of grains (Ciesla, 2007, 2009). Similar nebular environments were 860 suggested based on the measurements of oxygen isotopic and chemical zoning for intra-

861

862

863

864

865

866

867

868

869

870

871

872

873

874 Oxygen isotopic distributions and petrography of the V2-01 fluffy Type A CAI revealed 875

876

877

878

879

880

881

882

883

884 885 and inter- melilite crystals in Type A CAIs from Efremovka and Allende (Kawasaki et al., 2012; Park et al., 2012). As discussed in Section 4.3.5, our additional oxygen isotope data and the ${ }^{26} \mathrm{Al}-{ }^{26} \mathrm{Mg}$ systematics for $\mathrm{V} 2-01$ indicated that the oxygen isotopic composition of solar nebular gas surrounding the CAI changed from ${ }^{16} \mathrm{O}$-rich to ${ }^{16} \mathrm{O}$-poor and back to ${ }^{16} \mathrm{O}$-rich over a period of $0.18 \pm 0.07 \mathrm{Myr}$, which suggests that the solar nebular gas from which V2-01 formed changed in oxygen isotopic composition from ${ }^{16} \mathrm{O}$-rich to ${ }^{16} \mathrm{O}$-poor and back to ${ }^{16} \mathrm{O}$-rich during the first $0.18 \pm 0.07 \mathrm{Myr}$ of the Solar System. These findings imply that the radial excursion of the inner edge of the solar nebula, or radial transportation resulting in changes in the oxygen isotopic composition of the gas from which CAIs formed continued for at least $0.18 \pm 0.07 \mathrm{Myr}$.

\section{CONCLUSIONS}

the formation sequence and oxygen isotope change in the surrounding environment. The sequence is described as follows: (1) Spinel in the CAI interior formed in a ${ }^{16} \mathrm{O}$-rich reservoir $\left(\Delta^{17} \mathrm{O} \sim-24 \%\right.$ ) , while fassaite formed in a variable oxygen isotope reservoir $\left(\Delta^{17} \mathrm{O} \sim-12\right.$ and $-17 \%$ ). (2) Reversely zoned melilite crystals formed in a variable oxygen isotope reservoir changing from ${ }^{16} \mathrm{O}$-poor $\left(\Delta^{17} \mathrm{O}\right.$ values larger than $-10 \%$ ) to ${ }^{16} \mathrm{O}$-rich $\left(\Delta^{17} \mathrm{O} \sim-25 \%\right.$ ) and accumulated to form the V2-01 CAI precursor. A portion of melilite crystals enclosed pre-existing spinel and fassaite crystals. (3) W-L rim minerals formed in a ${ }^{16} \mathrm{O}$-rich reservoir $\left(\Delta^{17} \mathrm{O} \sim-23 \%\right.$ ). Variations of mass dependent magnesium isotopic fractionation observed in the reversely zoned melilite crystals that formed by condensation indicate a presence of a variable magnesium isotope gaseous reservoir in the solar nebula. 
887 The ${ }^{26} \mathrm{Al}^{-26} \mathrm{Mg}$ systematics are consistent with the inferred formation sequence. Spinel 888 in the CAI interior, six reversely zoned melilite crystals, and W-L rim minerals showed $889\left({ }^{26} \mathrm{Al} /{ }^{27} \mathrm{Al}\right)_{0}$ values of $(5.6 \pm 0.2) \times 10^{-5},(4.7 \pm 0.3) \times 10^{-5}$, and $(4.5 \pm 0.4) \times 10^{-5}$, 890 respectively. The oxygen isotope distributions and the ${ }^{26} \mathrm{Al}-{ }^{26} \mathrm{Mg}$ systematics indicated 891 that V2-01 formed over a period of $0.18 \pm 0.07 \mathrm{Myr}$ in a variable oxygen isotope 892 reservoir that changed from ${ }^{16} \mathrm{O}$-rich to ${ }^{16} \mathrm{O}$-poor and back to ${ }^{16} \mathrm{O}$-rich. The region of the 893 formation of V2-01 fluffy Type A CAI is suggested to correspond to the inner edge 894 region of the solar nebula where ${ }^{16} \mathrm{O}$-rich solar and ${ }^{16} \mathrm{O}$-poor planetary gases are 895 encountered and mixed (Yurimoto et al., 2008; Katayama et al., 2012). Our findings imply that the radial excursion of the inner edge of the solar nebula or radial transportation, resulting in changes in the oxygen isotopic composition of the gas from 899 which CAIs formed continued for at least $0.18 \pm 0.07 \mathrm{Myr}$.

901

902

\section{ACKNOWLEDGEMENTS}

903

This article is dedicated to Ian D. Hutcheon in honor of his outstanding contributions to 904 cosmochemistry. We thank Laurette Piani for helpful discussions. Constructive comments by Steve Simon, Andrew Needham and the Associate Editor Alexander N. Krot significantly improved the quality of the manuscript. This work is partly supported 907 by Monka-sho grants.

909

910

911

\section{REFERENCES}

Aléon J., El goresy A. and Zinner E. (2007) Oxygen isotope heterogeneities in the earliest protosolar gas recorded in a meteoritic calcium-aluminum-rich inclusion. Earth and Planetary Science Letters 263, 114-127.

914

915

916

Alexander C. M. O. D., Grossman J. N., Wang J., Zanda B., Bourot-Denis M. and Hewins R. H. (2000) The lack of potassium fractionation in Bishunpur chondrules. Meteoritics \& Planetary Science 35, 859-868.

Bullock E. S., Knight K. B., Richter F. M., Kita N. T., Ushikubo T., MacPherson G. J., Davis A. M. and Mendybaev R. A. (2013) Mg and Si fractionation patterns in types B1 and B2 CAIs: Implications for formation under different nebular conditions. Meteoritics \& Planetary Science 48, 1440-1458.

Catanzaro E. J., Murphy T. J., Garner E. L. and Shields W. R. (1966) Absolute isotopic abundance ratios and atomic weights of magnesium. J. Res. natl. Bur Stand. 70a, 
453-458.

Ciesla F. J. (2007) Outward transport of high-temperature materials around the midplane of the solar nebula. Science 318, 613-615.

Ciesla F. J. (2009) Two-dimensional transport of solids in viscous protoplanetary disks. Icarus 200, 655-671

Clayton R. N. (1993) Oxygen isotopes in meteorites. Annual Review of Earth and Planetary Science 21, 115-149.

Clayton R. N., Onuma N., Grossman L. and Mayeda T. K. (1977) Distribution of the presolar component in Allende and other carbonaceous chondrites. Earth and Planetary Science Letters 34, 209-224.

Connelly J. N., Bizzarro M., Krot A. N., Nordlund Å., Wielandt D. and Ivanova M. A. (2012) The absolute chronology and thermal processing of solids in the solar protoplanetary disk. Science 338, 651-655.

Davis A. M., Hashimoto A., Clayton R. N. and Mayeda T. K. (1990) Isotope mass fractionation during evaporation of $\mathrm{Mg}_{2} \mathrm{SiO}_{4}$. Nature 347, 655-658.

Davis A. M., Richter F. M., Mendybaev R. A., Janney P. E., Wadhwa M. and McKeegan K. D. (2015) Isotopic mass fractionation laws for magnesium and their effects on ${ }^{26} \mathrm{Al}-{ }^{26} \mathrm{Mg}$ systematics in solar system materials. Geochimica et Cosmochimica Acta 158, 245-261.

Fagan T. J., Krot A. N., Keil K. and Yurimoto H. (2004). Oxygen isotopic evolution of amoeboid olivine aggregates in the reduced CV3 chondrites Efremovka, Vigarano, and Leoville. Geochimica et Cosmochimica Acta 68, 2591-2611.

Galy A., Ash R. D. and O’Nions R. K. (2000) Formation of chondrules at high gas pressures in the solar nebula. Science 290, 1751-1754.

Grossman L. (1972) Condensation in the primitive solar nebula. Geochimica et Cosmochimica Acta 86, 597-619.

Grossman L., Ebel D. S. and Simon S. B. (2002) Formation of refractory inclusion by evaporation of condensate precursors. Geochimica et Cosmochimica Acta 66, 145-161.

Han J., Brearley A. J. and Keller L. P. (2015) Microstructural evidence for a disequilibrium condensation origin for hibonite-spinel inclusions in the ALHA77307 CO3.0 chondrite. Meteoritics \& Planetary Science 50, 2121-2136.

Harazono K. and Yurimoto H. (2003) Oxygen isotopic variations in a fluffy Type A CAI from the Vigarano meteorite. (abstract \#1540). 34th Lunar Planetary Science Conference. CD-ROM.

Ito M. and Ganguly J. (2009) Magnesium diffusion in minerals in CAIs: new 
experimental data for melilites and implications for the $\mathrm{Al}-\mathrm{Mg}$ chronometer and thermal history of CAIs. (abstract \#1753). 40th Lunar Planetary Science Conference.

Ito M. and Messenger S. (2010) Thermal metamorphic history of a Ca, Al-rich inclusion constrained by high spatial resolution $\mathrm{Mg}$ isotopic measurements with NanoSIMS 50L. Meteoritics \& Planetary Science 45, 583-595.

Ito M., Nagasawa H. and Yurimoto H. (2004) Oxygen isotopic SIMS analysis in Allende CAI: details of very early thermal history of the solar system. Geochimica et Cosmochimica Acta 68, 2905-2923.

Itoh S. and Yurimoto H. (2003) Contemporaneous formation of chondrules and refractory inclusions in the early solar system. Nature $\mathbf{4 2 3}, 728-731$.

Itoh S. Kojima H. and Yurimoto H. (2004) Petrography and oxygen isotopic compositions in refractory inclusions from $\mathrm{CO}$ chondrites. Geochimica et Cosmochimica Acta 68, 183-194.

Itoh S., Makide K. and Yurimoto H. (2008) Calculation of radiogenic ${ }^{26} \mathrm{Mg}$ of CAI minerals under high precision isotope measurement by SIMS. Applied Surface Science 255, 1476-1478.

Jacobsen B., Yin Q., Moynier F., Amelin Y., Krot A. N., Nagashima K., Hutcheon I. D. and Palme H. (2008) ${ }^{26} \mathrm{Al}-{ }^{26} \mathrm{Mg}$ and ${ }^{207} \mathrm{~Pb}-{ }^{206} \mathrm{~Pb}$ systematics of Allende CAIs: Canonical solar initial ${ }^{26} \mathrm{Al} /{ }^{27} \mathrm{Al}$ ratio reinstated. Earth and Planetary Science Letters 272, 353-364.

Katayama J., Itoh S. and Yurimoto H. (2012) Oxygen isotopic zoning of reversely zoned melilite crystals in a Fluffy Type A Ca-Al-rich inclusion from the Vigarano meteorite. Meteoritics \& Planetary Science 47, 2094-2106.

Kawasaki N., Sakamoto N. and Yurimoto H. (2012) Oxygen isotopic and chemical zoning of melilite crystals in a Type A Ca-Al-rich inclusion of Efremovka CV3 chondrite. Meteoritics \& Planetary Science 47, 2084-2093.

Kawasaki, N., Kato, C., Itoh, S., Wakaki, S., Ito, M. and Yurimoto, H. (2015) ${ }^{26} \mathrm{Al}-{ }^{26} \mathrm{Mg}$ chronology and oxygen isotope distributions of multiple melting for a Type $\mathrm{C}$ CAI from Allende. Geochimica et Cosmochimica Acta 169, 99-114.

Kita N. T., Ushikubo T., Knight K.B., Mendybaev R. A., Davis A. M., Richter F. M. and Fournelle J. H. (2012) Internal ${ }^{26} \mathrm{Al}-{ }^{26} \mathrm{Mg}$ isotope systematics of a Type B CAI: Remelting of refractory precursor solids. Geochimica et Cosmochimica Acta 86, 37-51.

Krot A. N., Yurimoto H., Hutcheon I. D. and MacPherson G. J. (2005) Chronology of the early Solar System from chondrule-bearing calcium-aluminium-rich 
inclusions. Nature 434, 998-1001.

Krot A. N., Yurimoto H., Hutcheon I. D., Chaussidon M., MacPherson G. J. and Paque J. (2007) Remelting of refractory inclusions in the chondrule-forming regions: Evidence from chondrule-bearing type $\mathrm{C}$ calcium-aluminum-rich inclusions from Allende. Meteoritics \& Planetary Science 42, 1197-1219.

Krot A. N., Chaussidon M., Yurimoto H., Sakamoto N., Nagashima K., Hutcheon I. D. and MacPherson G. J. (2008) Oxygen isotopic compositions of Allende Type C CAIs: Evidence for isotopic exchange during nebular melting and asteroidal metamorphism. Geochimica et Cosmochimica Acta 72, 2534-2555.

Larsen K. K., Trinquier A., Paton C., Schiller M., Wielandt D., Ivanova M. A., Connelly J. N., Nordlund Å., Krot A. N. and Bizzarro M. (2011) Evidence for magnesium isotope heterogeneity in the solar protoplanetary disk. The Astrophysical Journal Letters 735, L37-L43.

Lee T., Papanastassiou D. A. and Wasserburg G. J. (1976) Demonstration of Mg-26 excess in Allende and evidence for Al-26. Geophysical Research Letters 3, $41-44$.

Liermann H-P. and Ganguly J. (2002) Diffusion kinetics of $\mathrm{Fe}^{2+}$ and $\mathrm{Mg}$ in aluminous spinel: Experimental determination and applications. Geochimca et Cosmochimca Acta 66, 2903-2913.

MacPherson G. J. and Grossman L. (1984) Fluffy Type A Ca-, Al-rich inclusions in the Allende meteorite. Geochimica et Cosmochimica Acta 48, 29-46.

MacPherson G. J. and Davis A. M. (1994) Refractory inclusions in the prototypical CM chondrite, Mighei. Geochimica et Cosmochimica Acta 58, 5599-5625.

MacPherson G. J., Davis A. M. and Zinner E. K. (1995) The distribution of aluminum-26 in the early Solar System-A reappraisal. Meteoritics 30, 365-386.

MacPherson G. J., Grossman L., Hashimoto A., Bar-Matthews M. and Tanaka T. (1984) Petrographic studies of refractory inclusions from the Murchison meteorite (abstract). 15th Lunar and Planetary Science Conference. Journal of Geophysical Research 89. C299-C312.

MacPherson G. J., Bullock E. S., Janney P. E., Kita N. T., Ushikubo T., Davis A. M., Wadhwa M. and Krot A. N. (2010) Early solar nebula condensate with canonical, not supracanonical, initial ${ }^{26} \mathrm{Al} /{ }^{27} \mathrm{Al}$ ratios. The Astrophysical Journal Letters $\mathbf{7 1 1}$, L117-L121.

MacPherson G. J., Kita N. T., Ushikubo T., Bullock E. S. and Davis A. M. (2012) Well-resolved variations in the formation ages for Ca-Al-rich inclusions in the early Solar System. Earth and Planetary Science Letters 331-332, 43-54. 
1039

1040

1041

1042

1043

1044

1045

1046

1047

1048

1049

1050

1051

1052

1053

1054

1055

1056

1057

1058

1059

1060

1061

1062

1063

1064

1065

Mendybaev R. A., Richter F. M., Georg R. B. Janney P. E., Spicuzza M. J., Davis A. M. and Valley J. W. (2013) Experimental evaporation of Mg- and Si-rich melts: Implications for the origin and evolution of FUN CAIs. Geochimica et Cosmochimica Acta 123, 368-384.

Mishra R. K. and Chaussidon M. (2014) Timing and extent of Mg and Al isotopic homogenization in the early inner Solar System. Earth and Planetary Science Letters 390, 318-326.

Norris T. L., Gancarz A. J., Rokop D. J. and Thomas K. W. (1983) Half-life of ${ }^{26}$ Al. J. Geophys. Res. 88, B331-B333.

Osborn E. and Schairar J. F. (1941) The ternary system pseudowollastonite-åkermanite-gehlenite. American Journal of Science 239, 715-763.

Ozawa K. and Nagahara H. (2001) Chemical and isotopic fractionations by evaporation and their cosmochemical implications. Geochimica et Cosmochimica Acta 65, 2171-2199.

Park C., Nagashima K., Wakaki S., Sakamoto N., Kobayashi S. and Yurimoto H. (2014) Gehlenitic mantle formation of a compact Type A CAI from Allende. (abstract \#5038). 77th Annual Meteoritical Society Meeting.

Park C., Wakaki S., Sakamoto N., Kobayashi S. and Yurimoto H. (2012) Oxygen isotopic variations of melilite crystals in a Type A CAI from Allende. Meteoritics \& Planetary Science 47, 2070-2083.

Richter F. M., Davis A. M., Ebel D. S. and Hashimoto A. (2002) Elemental and isotopic fractionation of Type B calcium-, aluminum-rich inclusions: experiments, theoretical considerations, and constraints on their thermal evolution. Geochimica et Cosmochimica Acta 66, 521-540.

Richter F. M., Janney P. E., Mendybaev R. A., Davis A. M. and Wadhwa M. (2007) Elemental and isotopic fractionation of Type B CAI-like liquids by evaporation. Geochimica et Cosmochimica Acta 71, 5544-5564.

Ryerson F. J. and McKeegan K. D. (1994) Determination of oxygen self-diffusion in åkermanite, anorthite, diopside, and spinel: Implications for oxygen isotopic anomalies and the thermal histories of Ca-Al-rich inclusions. Geochimca et Cosmochimca Acta 58, 3713-3734.

Shu F. H., Shang H., Glassgold A. E. and Lee T. (1997) X-rays and fluctuating X-winds from protostars. Science 277, 1475-1479.

Simon J. I., Hutcheon I. D., Simon S. B., Matzel J. E. P., Ramon E. C., Weber P. K., Grossman L. and DePaolo D. J. (2011) Oxygen isotope variations at the margin 
of a CAI records circulation within the solar nebula. Science 331, 1175-1178.

Simon J. I., Young E. D., Russell S. S., Tonui E. K., Dyl K. A. and Manning C. E. (2005) Earth and Planetary Science Letters 238, 272-283.

Simon S. B., Grossman L., Hutcheon I. D., Phinney D. L., Weber P. K. and Fallon S. J. (2006) Formation of spinel-, hibonite-rich inclusions found in CM2 carbonaceous chondrites. American Mineralogist 91, 1675-1687.

Stolper E. (1982) Crystallization sequence of Ca-Al-rich inclusions from Allende: An experimental study. Geochimca et Cosmochimca Acta 46, 2159-2180.

Wakaki S., Itoh S., Tanaka T. and Yurimoto H. (2011) High-precision Al-Mg dating of anorthite in a compound object of CAI-chondrule from Allende. (abstract \#9050) Formation of the First Solids in the Solar System.

Wakaki S., Itoh S., Tanaka T. and Yurimoto H. (2013) Petrology, trace element abundances and oxygen isotopic compositions of a compound CAI-chondrule object from Allende. Geochimica et Cosmochimica Acta 102, 261-279.

Wark D. A. (2005) The first step in CAI rim formation: Flash heating or subsolidus evaporation? (abstract \#1643). 36th Lunar and Planetary Science Conference.

Wark D. A. and Boynton W. V. (2001) The formation of rims on calcium-aluminum-rich inclusions: Step I-Flash heating. Meteoritics \& Planetary Science 36, 1135-1166.

Wark D. A. and Lovering J. F. (1977) Marker events in the early solar system: evidence from rims on $\mathrm{Ca}-\mathrm{Al}$-rich inclusions in carbonaceous chondrites. Proceedings, 8th Lunar and Planetary Science Conference. pp. 95-112.

Wasson J. T., Yurimoto H. and Russell S. S. (2001) ${ }^{16} \mathrm{O}$-rich melilite in $\mathrm{CO} 3.0$ chondrites: Possible formation of common, ${ }^{16} \mathrm{O}$-poor melilite by aqueous alteration. Geochimica et Cosmochimica Acta 65, 4539-4549.

Wood J. A. and Hashimoto A. (1993) Mineral equilibrium in fractionated nebular systems. Geochimica et Cosmochimica Acta 57, 2377-2388.

Yoneda S. and Grossman L. (1995) Condensation of $\mathrm{CaO}-\mathrm{MgO}-\mathrm{Al}_{2} \mathrm{O}_{3}-\mathrm{SiO}_{2}$ liquids from cosmic gases. Geochimica et Cosmochimica Acta 59, 3413-3444.

Yoshitake M., Koide Y. and Yurimoto H. (2005) Correlations between oxygen-isotopic composition and petrologic setting in a coarse-grained $\mathrm{Ca}$, Al-rich inclusion. Geochimica et Cosmochimica Acta 69, 2663-2674.

Yurimoto H. and Kuramoto K. (2004) Molecular cloud origin for the oxygen isotope heterogeneity in the solar system. Science 305, 1763-1766.

Yurimoto H., Ito M. and Nagasawa H. (1998) Oxygen isotope exchange between refractory inclusion in Allende and solar nebula gas. Science 282, 1874-1877. 
1102 Yurimoto H., Morioka M. and Nagasawa H. (1989) Diffusion in single crystals of 1103 melilite: I. Oxygen. Geochimica et Cosmochimica Acta 53, 2387-2394.

1104 Yurimoto H., Nagasawa H., Mori Y. and Matsubaya O. (1994) Micro-distribution of 1105 oxygen isotopes in a refractory inclusion from the Allende meteorite. Earth and Planetary Science Letters 128, 47-53.

1107 Yurimoto H., Krot N. K., Choi B., Aléon J., Kunihiro T. and Brearley A. J. (2008) 1108 Oxygen isotopes in chondritic components. In Oxygen in the Solar System, 1109 edited by MacPherson G. J. Reviews in Mineralogy and Geochemistry, vol. 68. Washington, D. C.: Mineralogical Society of America. pp. 141-186.

1111 
1112 Table 1. Representative compositions of diopside, fassaite, and spinel in V2-01.

\begin{tabular}{|c|c|c|c|c|c|c|c|c|}
\hline \multirow[b]{2}{*}{$\mathrm{wt} \%$} & \multicolumn{4}{|c|}{ CAI interior } & \multicolumn{4}{|c|}{ W-L rim } \\
\hline & Fas & Fas & $\mathrm{Sp}$ & $\mathrm{Sp}$ & $\mathrm{Di}$ & $\mathrm{Di}$ & $\mathrm{Sp}$ & $\mathrm{Sp}$ \\
\hline $\mathrm{MgO}$ & 5.9 & 8.1 & 27.9 & 27.4 & 17.9 & 14.8 & 27.8 & 27.4 \\
\hline $\mathrm{Al}_{2} \mathrm{O}_{3}$ & 20.8 & 17.4 & 71.2 & 70.0 & 0.3 & 8.6 & 71.0 & 71.1 \\
\hline $\mathrm{SiO}_{2}$ & 31.9 & 36.7 & n.d. & n.d. & 55.3 & 49.6 & n.d. & n.d. \\
\hline $\mathrm{CaO}$ & 24.5 & 24.7 & n.d. & n.d. & 26.1 & 25.8 & n.d. & n.d. \\
\hline $\mathrm{TiO}_{2}$ & 15.1 & 11.9 & 0.3 & 0.2 & n.d. & 1.4 & 0.4 & 0.3 \\
\hline $\mathrm{V}_{2} \mathrm{O}_{5}$ & 1.7 & 1.1 & 1.0 & 1.2 & n.d. & n.d. & 0.4 & 0.5 \\
\hline $\mathrm{FeO}$ & n.d. & n.d. & n.d. & 0.3 & n.d. & n.d. & 0.2 & 0.8 \\
\hline Total & 99.9 & 100.0 & 100.4 & 99.0 & 99.6 & 100.1 & 99.8 & 100.0 \\
\hline \multicolumn{9}{|l|}{ Cations } \\
\hline $\mathrm{Mg}$ & 0.33 & 0.45 & 0.98 & 0.98 & 0.97 & 0.80 & 0.98 & 0.97 \\
\hline $\mathrm{Al}$ & 0.91 & 0.76 & 1.98 & 1.97 & 0.01 & 0.36 & 1.99 & 1.99 \\
\hline $\mathrm{Si}$ & 1.19 & 1.36 & n.d. & n.d. & 2.00 & 1.79 & n.d. & n.d. \\
\hline $\mathrm{Ca}$ & 0.98 & 0.98 & n.d. & n.d. & 1.01 & 1.00 & n.d. & n.d. \\
\hline $\mathrm{Ti}$ & 0.42 & 0.33 & 0.01 & 0.00 & n.d. & 0.04 & 0.01 & 0.00 \\
\hline V & 0.04 & 0.03 & 0.02 & 0.02 & n.d. & n.d. & 0.01 & 0.01 \\
\hline $\mathrm{Fe}$ & n.d. & n.d. & n.d. & 0.01 & n.d. & n.d. & 0.00 & 0.02 \\
\hline Total & 3.87 & 3.89 & 2.98 & 2.98 & 3.99 & 3.99 & 2.99 & 2.99 \\
\hline per oxygen & 6 & 6 & 4 & 4 & 6 & 6 & 4 & 4 \\
\hline
\end{tabular}

1113

Di: diopside, Fas: fassaite, Sp: spinel, n.d. = not detected

1114

1115 
1116 Table 2. Oxygen isotopic compositions (\%o) of diopside, fassaite, and spinel in V2-01.

\begin{tabular}{ccccccc}
\hline Mineral & $\delta^{17} \mathrm{O}$ & $2 \sigma$ & $\delta^{18} \mathrm{O}$ & $2 \sigma$ & $\Delta^{17} \mathrm{O}$ & $2 \sigma$ \\
\hline \multicolumn{7}{c}{ CAI interior } \\
Fas & -32.1 & 2.2 & -29.5 & 1.8 & -16.8 & 2.0 \\
Fas & -19.1 & 2.0 & -17.1 & 2.1 & -10.2 & 2.1 \\
Fas & -20.8 & 2.2 & -16.3 & 1.7 & -12.3 & 2.1 \\
Fas & -20.4 & 2.2 & -15.7 & 2.1 & -12.2 & 2.0 \\
Sp & -47.8 & 2.1 & -44.7 & 1.6 & -24.5 & 2.1 \\
Sp & -46.1 & 1.8 & -44.0 & 1.4 & -23.3 & 1.6 \\
Sp & -47.4 & 2.3 & -45.9 & 2.0 & -23.5 & 2.0 \\
\hline \multicolumn{7}{c}{ W-L rim } \\
Di & -44.0 & 2.3 & -42.3 & 1.4 & -22.0 & 2.4 \\
Di & -45.5 & 1.8 & -42.0 & 1.4 & -23.7 & 1.8 \\
Sp & -45.8 & 2.1 & -44.0 & 1.3 & -22.9 & 2.0 \\
Sp & -45.2 & 1.9 & -42.9 & 1.7 & -22.9 & 1.6 \\
\hline Di
\end{tabular}

1117

Di: diopside, Fas: fassaite Sp: spinel

1118

1119 
1120 Table 3. Magnesium isotopic compositions (\%o) and ${ }^{27} \mathrm{Al} /{ }^{24} \mathrm{Mg}$ ratios of diopside, 1121 fassaite, and spinel in V2-01.

\begin{tabular}{|c|c|c|c|c|c|c|}
\hline Mineral & ${ }^{27} \mathrm{Al} /{ }^{24} \mathrm{Mg}$ & $2 \sigma$ & $\delta^{26} \mathrm{Mg} *$ & $2 \sigma$ & $\delta^{25} \mathrm{Mg}$ & $2 \sigma$ \\
\hline \multicolumn{7}{|c|}{ CAI interior } \\
\hline Fas & 3.45 & 0.02 & 1.39 & 0.14 & - & - \\
\hline Fas & 2.49 & 0.04 & 1.01 & 0.13 & - & - \\
\hline Fas & 3.77 & 0.05 & 1.44 & 0.13 & - & - \\
\hline Fas & 3.66 & 0.03 & 1.48 & 0.15 & - & - \\
\hline $\mathrm{Sp}$ & 2.48 & 0.00 & 0.98 & 0.14 & -0.62 & 0.06 \\
\hline $\mathrm{Sp}$ & 2.48 & 0.00 & 0.97 & 0.14 & -0.61 & 0.06 \\
\hline $\mathrm{Sp}$ & 2.47 & 0.00 & 0.95 & 0.14 & -0.64 & 0.05 \\
\hline $\mathrm{Sp}$ & 2.48 & 0.00 & 1.03 & 0.13 & -0.08 & 0.05 \\
\hline $\mathrm{Sp}$ & 2.50 & 0.00 & 1.05 & 0.16 & -0.53 & 0.05 \\
\hline $\mathrm{Sp}$ & 2.47 & 0.00 & 0.97 & 0.13 & -0.66 & 0.05 \\
\hline $\mathrm{Sp}$ & 2.48 & 0.00 & 1.03 & 0.14 & -0.68 & 0.06 \\
\hline $\mathrm{Sp}$ & 2.47 & 0.00 & 0.92 & 0.11 & 0.30 & 0.08 \\
\hline $\mathrm{Sp}$ & 2.48 & 0.00 & 1.01 & 0.11 & 0.61 & 0.08 \\
\hline $\mathrm{Sp}$ & 2.49 & 0.00 & 0.98 & 0.13 & 0.69 & 0.07 \\
\hline $\mathrm{Sp}$ & 2.48 & 0.00 & 0.99 & 0.11 & 0.30 & 0.06 \\
\hline $\mathrm{Sp}$ & 2.49 & 0.00 & 0.91 & 0.13 & 0.02 & 0.05 \\
\hline \multicolumn{7}{|c|}{ W-L rim } \\
\hline Di & 0.02 & 0.00 & -0.02 & 0.13 & - & - \\
\hline Di & 0.42 & 0.03 & 0.08 & 0.10 & - & - \\
\hline Di & 0.49 & 0.02 & 0.04 & 0.11 & - & - \\
\hline Di & 0.04 & 0.00 & -0.02 & 0.12 & - & - \\
\hline Di & 0.04 & 0.00 & 0.00 & 0.09 & - & - \\
\hline $\mathrm{Sp}$ & 2.49 & 0.00 & 0.76 & 0.13 & 0.02 & 0.04 \\
\hline $\mathrm{Sp}$ & 2.51 & 0.00 & 0.70 & 0.11 & 0.94 & 0.07 \\
\hline $\mathrm{Sp}$ & 2.51 & 0.00 & 0.79 & 0.11 & 0.92 & 0.08 \\
\hline $\mathrm{Sp}$ & 2.53 & 0.00 & 0.81 & 0.11 & 1.04 & 0.08 \\
\hline $\mathrm{Sp}$ & 2.49 & 0.00 & 0.75 & 0.13 & 0.76 & 0.06 \\
\hline $\mathrm{Sp}$ & 2.49 & 0.00 & 0.77 & 0.14 & 0.62 & 0.07 \\
\hline $\mathrm{Sp}$ & 2.51 & 0.00 & 0.75 & 0.12 & 0.67 & 0.07 \\
\hline $\mathrm{Sp}$ & 2.50 & 0.00 & 0.81 & 0.12 & 0.80 & 0.10 \\
\hline $\mathrm{Sp}$ & 2.51 & 0.00 & 0.80 & 0.11 & 0.84 & 0.07 \\
\hline
\end{tabular}


1125 Table 4. Magnesium isotopic compositions (\%o) and ${ }^{27} \mathrm{Al} /{ }^{24} \mathrm{Mg}$ ratios of melilite 1126 crystals in V2-01.

\begin{tabular}{|c|c|c|c|c|c|c|c|c|c|c|c|c|c|c|c|}
\hline Grain & \# & ${ }^{27} \mathrm{Al} /{ }^{24} \mathrm{Mg}$ & $2 \sigma$ & $\delta^{26} \mathrm{Mg}^{*}$ & $2 \sigma$ & $\delta^{25} \mathrm{Mg}$ & $2 \sigma$ & Grain & \# & ${ }^{27} \mathrm{Al} /{ }^{24} \mathrm{Mg}$ & $2 \sigma$ & $\delta^{26} \mathrm{Mg}^{*}$ & $2 \sigma$ & $\delta^{25} \mathrm{Mg}$ & $2 \sigma$ \\
\hline 1 & 87 & 18.91 & 0.07 & 6.1 & 1.2 & 2.2 & 1.0 & 9 & 182 & 35.34 & 0.15 & 12.8 & 1.2 & 7.9 & 0.9 \\
\hline 1 & 89 & 47.36 & 0.18 & 16.4 & 1.1 & 0.7 & 1.0 & 9 & 183 & 44.89 & 0.13 & 15.5 & 1.0 & 9.7 & 0.9 \\
\hline 1 & 90 & 44.00 & 0.49 & 15.2 & 1.7 & 0.1 & 1.2 & 9 & 184 & 43.79 & 0.13 & 15.3 & 1.0 & 8.5 & 0.8 \\
\hline 1 & 91 & 28.56 & 0.07 & 9.4 & 1.0 & 0.2 & 1.0 & 9 & 186 & 30.20 & 0.09 & 10.6 & 1.4 & 6.1 & 1.0 \\
\hline 1 & 95 & 24.87 & 0.27 & 8.7 & 1.7 & 1.1 & 1.1 & 9 & 187 & 27.45 & 0.05 & 8.7 & 1.2 & 5.7 & 0.9 \\
\hline 1 & 96 & 32.28 & 0.37 & 10.9 & 1.0 & 1.1 & 0.9 & 9 & 191 & 14.39 & 0.04 & 5.3 & 1.1 & 3.0 & 0.9 \\
\hline 1 & 97 & 13.67 & 0.15 & 5.0 & 1.2 & 3.5 & 0.9 & 9 & 192 & 14.58 & 0.08 & 4.7 & 1.0 & 3.3 & 0.8 \\
\hline 1 & 99 & 8.16 & 0.08 & 2.5 & 1.5 & 6.4 & 0.9 & 9 & 227 & 35.68 & 0.23 & 12.9 & 1.0 & 7.5 & 0.9 \\
\hline 1 & 100 & 30.66 & 0.35 & 10.0 & 1.1 & 2.4 & 0.8 & 9 & 229 & 20.60 & 0.11 & 8.3 & 1.2 & 4.0 & 1.0 \\
\hline 1 & 116 & 6.89 & 0.01 & 3.2 & 1.2 & 5.6 & 0.8 & 9 & 230 & 15.68 & 0.08 & 5.2 & 0.9 & 4.2 & 1.0 \\
\hline 1 & 117 & 50.04 & 0.27 & 17.4 & 1.1 & 0.1 & 0.8 & 9 & 232 & 10.48 & 0.05 & 3.7 & 1.0 & 4.0 & 0.9 \\
\hline 1 & 118 & 11.24 & 0.04 & 5.0 & 1.1 & 4.8 & 0.8 & 15 & 269 & 11.05 & 0.03 & 3.9 & 1.1 & 4.8 & 0.7 \\
\hline 3 & 67 & 33.34 & 0.08 & 11.5 & 1.3 & 1.7 & 0.7 & 15 & 270 & 16.96 & 0.08 & 5.4 & 0.9 & 4.2 & 0.7 \\
\hline 3 & 86 & 16.32 & 0.06 & 6.2 & 1.1 & 2.1 & 1.0 & 15 & 271 & 132.44 & 4.26 & 45.8 & 2.5 & 1.1 & 1.5 \\
\hline 3 & 277 & 10.29 & 0.03 & 3.1 & 1.1 & 2.4 & 0.7 & 15 & 272 & 17.23 & 0.10 & 4.9 & 0.9 & 4.2 & 0.6 \\
\hline 3 & 278 & 26.97 & 0.11 & 8.7 & 0.9 & 2.0 & 0.7 & 15 & 273 & 13.97 & 0.05 & 4.2 & 1.1 & 5.6 & 0.8 \\
\hline 3 & 285 & 22.42 & 0.31 & 7.7 & 1.4 & 1.6 & 0.9 & 15 & 274 & 21.37 & 0.10 & 7.3 & 0.8 & 2.2 & 0.6 \\
\hline 3 & 286 & 28.73 & 0.27 & 10.0 & 0.9 & 1.6 & 0.8 & 15 & 275 & 84.68 & 0.97 & 28.3 & 2.3 & 1.5 & 1.6 \\
\hline 3 & 289 & 13.31 & 0.12 & 4.7 & 0.9 & 1.7 & 0.8 & 15 & 276 & 21.10 & 0.09 & 6.1 & 0.9 & 4.3 & 0.7 \\
\hline 3 & 290 & 10.19 & 0.10 & 3.6 & 1.4 & 2.1 & 0.9 & 21 & 233 & 11.83 & 0.05 & 4.9 & 1.3 & 1.2 & 1.0 \\
\hline 8 & 101 & 27.86 & 0.31 & 10.5 & 1.4 & 1.8 & 0.9 & 21 & 234 & 17.32 & 0.07 & 6.1 & 1.3 & 1.5 & 1.0 \\
\hline 8 & 102 & 22.95 & 0.24 & 8.8 & 1.2 & 1.2 & 0.9 & 21 & 235 & 23.93 & 0.09 & 8.3 & 1.0 & 0.9 & 0.9 \\
\hline 8 & 103 & 39.81 & 0.44 & 13.8 & 1.0 & 3.6 & 0.8 & 21 & 236 & 36.44 & 0.51 & 12.4 & 1.6 & 0.6 & 1.1 \\
\hline 8 & 104 & 19.06 & 0.21 & 5.9 & 1.1 & 0.6 & 0.8 & 21 & 237 & 46.98 & 3.17 & 17.0 & 1.9 & 0.9 & 1.1 \\
\hline 8 & 119 & 34.02 & 0.17 & 12.2 & 1.2 & 1.2 & 0.9 & 21 & 238 & 24.89 & 0.14 & 9.2 & 1.2 & 1.7 & 0.9 \\
\hline 8 & 120 & 40.19 & 0.33 & 13.7 & 1.1 & 4.6 & 0.9 & 21 & 264 & 18.01 & 0.06 & 5.5 & 1.2 & 2.4 & 0.7 \\
\hline 8 & 121 & 24.37 & 0.09 & 8.1 & 1.3 & 1.8 & 0.8 & 21 & 265 & 27.43 & 0.09 & 8.9 & 0.9 & 0.8 & 0.7 \\
\hline 8 & 122 & 15.01 & 0.10 & 5.4 & 1.1 & 0.9 & 0.9 & 21 & 266 & 44.25 & 0.16 & 15.1 & 1.3 & 1.3 & 0.8 \\
\hline 8 & 123 & 33.17 & 0.13 & 11.1 & 1.3 & 3.0 & 0.9 & 21 & 267 & 146.14 & 1.20 & 47.7 & 1.9 & 2.1 & 1.1 \\
\hline 8 & 125 & 52.96 & 0.38 & 18.0 & 1.3 & 3.8 & 0.8 & 21 & 268 & 41.28 & 0.43 & 13.1 & 1.4 & 1.5 & 0.8 \\
\hline 8 & 126 & 40.19 & 0.25 & 13.6 & 1.2 & 2.5 & 0.7 & & & & & & & & \\
\hline 8 & 181 & 21.92 & 0.05 & 8.6 & 1.2 & 0.8 & 0.9 & & & & & & & & \\
\hline
\end{tabular}



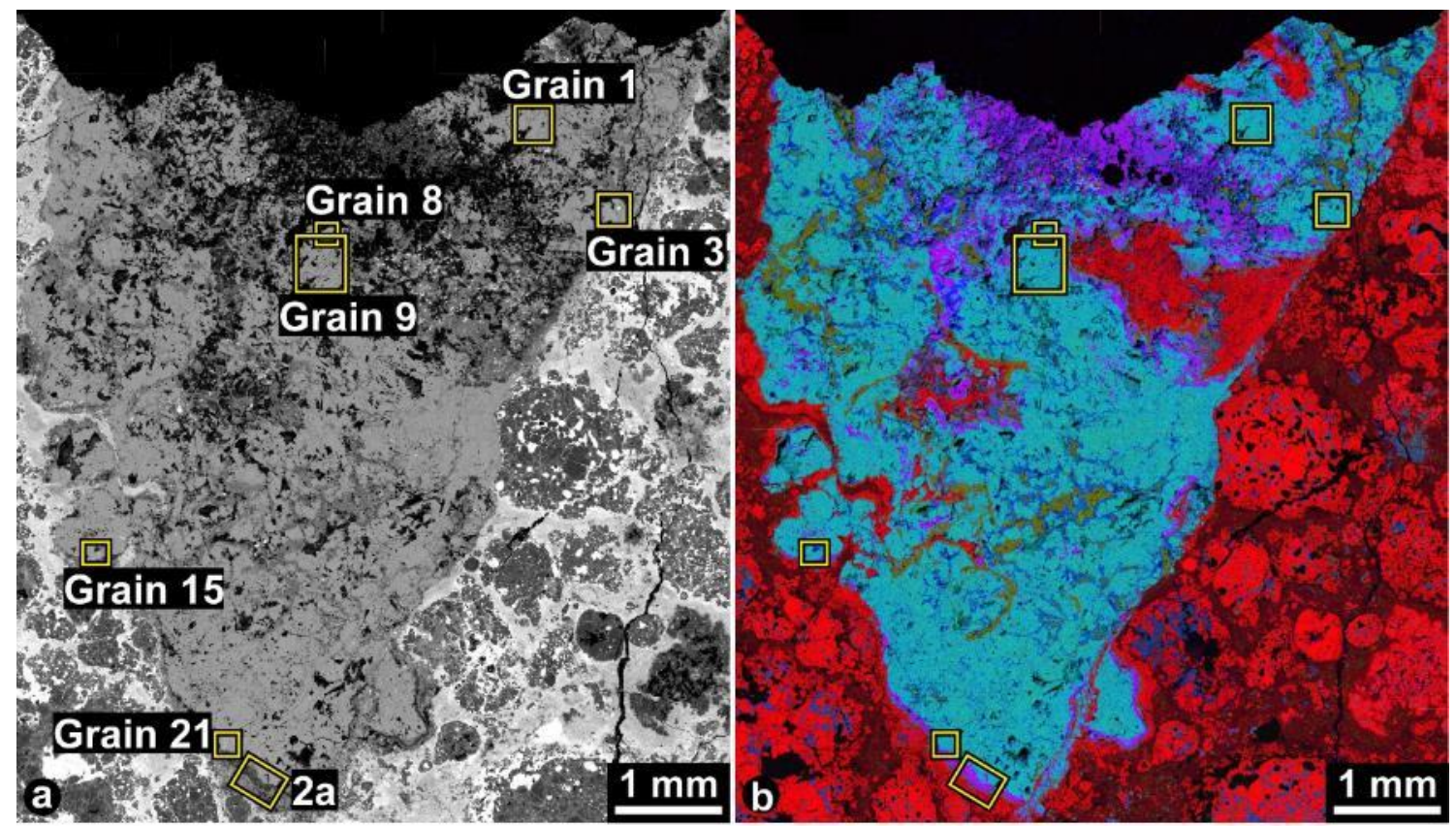

1131 Figure 1. (a) Backscattered electron (BSE) image of the fluffy Type A CAI, V2-01, 1132 from the Vigarano CV3 chondrite. Yellow boxes indicate areas containing grains 1, 3, 1133 8, 9, 15, and 21 (Fig. 3); one box, labeled "2a", is shown in Fig 2a. (b) Combined 1134 X-ray elemental map of V2-01 with $\mathrm{Mg}$ (red), $\mathrm{Ca}$ (green), and $\mathrm{Al}$ (blue). 

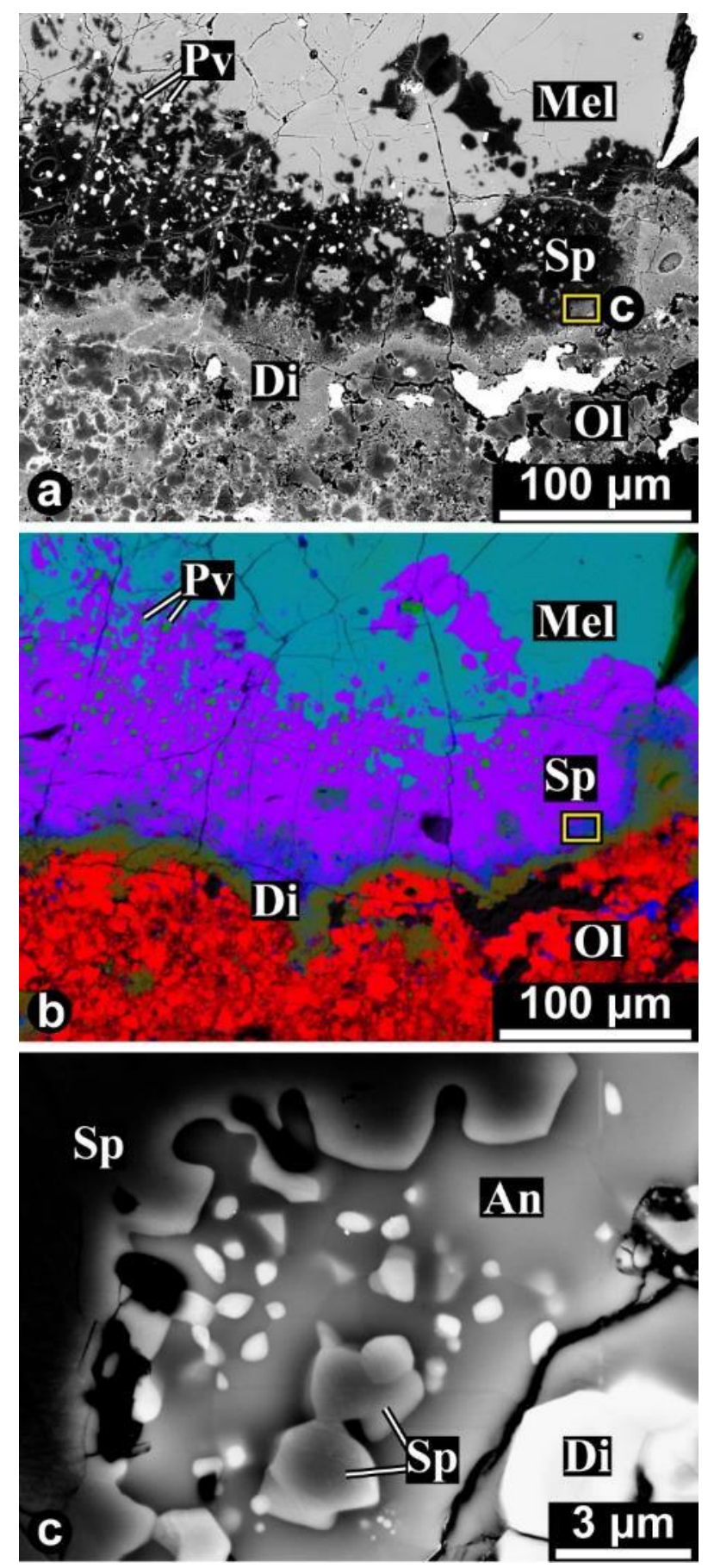

1137 Figure 2. (a) BSE image of the Wark-Lovering rim (W-L rim) in the area of V2-01 1138 indicated by box 2a in Fig. 1a. (b) Combined X-ray elemental map of the area in (a) 1139 with $\mathrm{Mg}$ (red), Ca (green), and Al (blue). (c) Magnified BSE image of the area 1140 indicated by box (c) in (a). An, anorthite; Di, diopside; Mel, melilite; Ol, olivine; Pv, 1141 perovskite; Sp, spinel. 

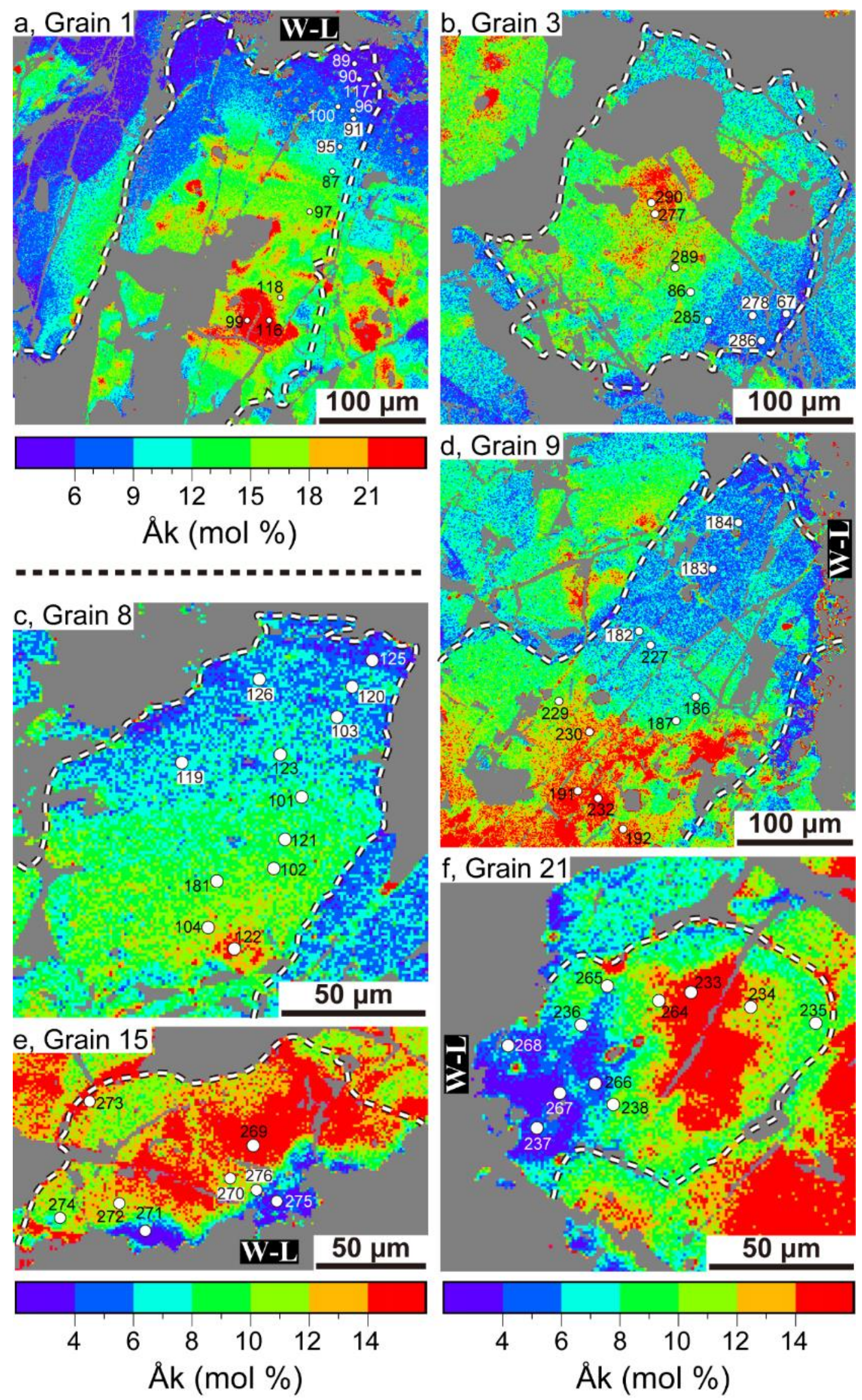
1144 Figure 3. X-ray elemental maps corresponding to åkermanite contents of reversely 1145 zoned melilite crystals and measurement positions for magnesium isotopic 1146 compositions and ${ }^{27} \mathrm{Al} /{ }^{24} \mathrm{Mg}$ ratios. Color bars indicate åkermanite contents. Other 1147 mineral phases and polishing flaws are masked by grey color. Circles indicate 1148 measurement positions for Al-Mg isotopes. Numbers of each point correspond to the 1149 entries listed in Table 4. Data for X-ray elemental maps were obtained from literature 1150 (after Katayama et al., 2012). Dashed lines indicate grain boundaries determined 1151 through electron backscattered diffraction (EBSD) analysis. W-L is the Wark-Lovering 1152 rim.

1153 

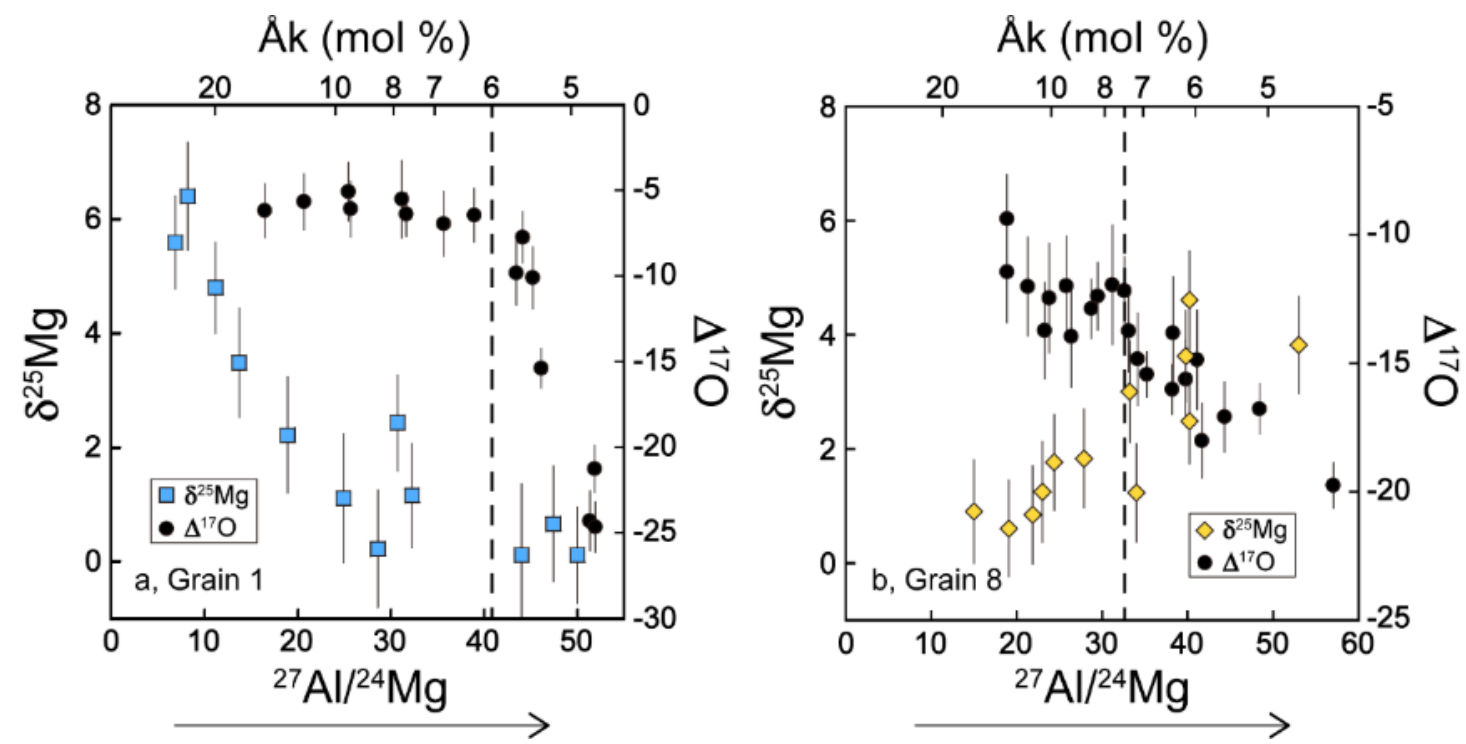

1154

1155 Figure 4. Relationships between the oxygen isotopic composition, the $\delta^{25} \mathrm{Mg}$ values, 1156 and the chemical composition of reversely zoned melilite crystals. (a) grain 1; (b) 1157 grain 8. Dashed lines indicate the chemical compositions at which the oxygen isotopic 1158 compositions started to change. Arrows correspond to directions of compositional 1159 change with the growth of reversely zoned melilite crystals. Oxygen isotopic 1160 compositions are from Katayama et al. (2012). 


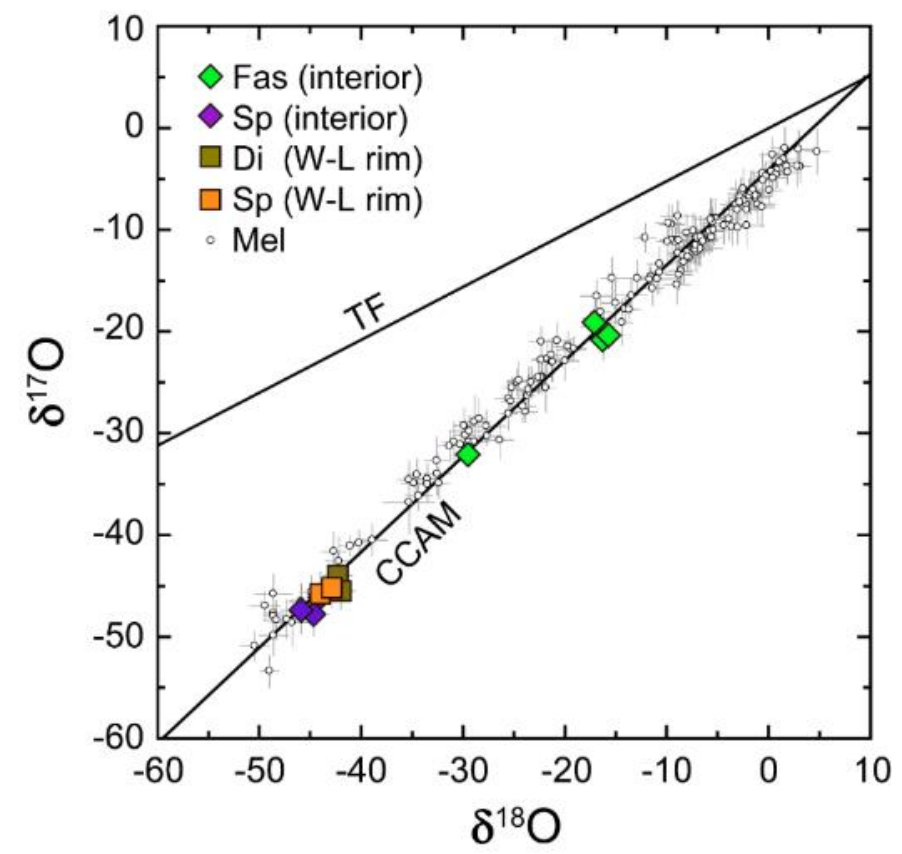

1162

1163 Figure 5. Oxygen isotopic compositions of diopside, fassaite, and spinel in V2-01. The

1164 oxygen isotopic compositions of melilite (Katayama et al., 2012) are plotted for 1165 comparison. Error bars are $2 \sigma$. TF, terrestrial fractionation line; CCAM, carbonaceous 1166 chondrite anhydrous mineral line; W-L, the Wark-Lovering rim; Di, diopside; Fas, 1167 fassaite; Mel, melilite; Sp, spinel.

1168 


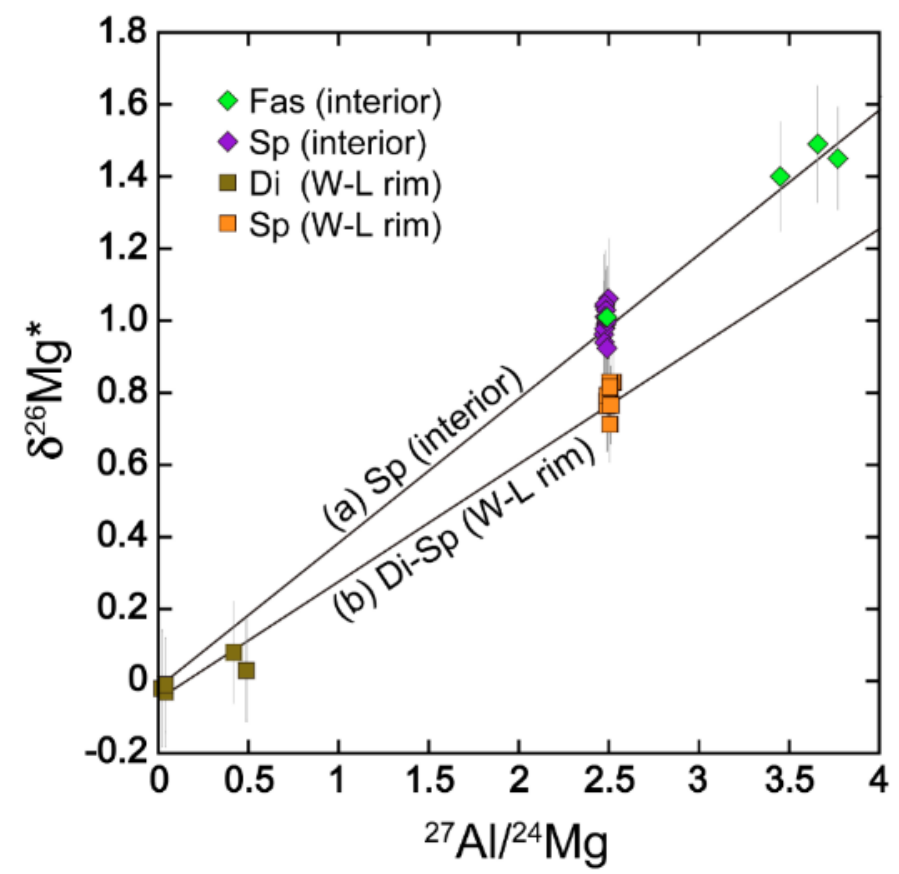

1169

Figure 6. ${ }^{26} \mathrm{Al}-{ }^{26} \mathrm{Mg}$ isochrons of V2-01. (a) Model isochron, $\left({ }^{26} \mathrm{Al} /{ }^{27} \mathrm{Al}\right)_{0}=(5.6 \pm 0.2)$ $1171 \times 10^{-5}$, of spinel in the CAI interior assuming a solar initial $\left(\delta^{26} \mathrm{Mg}^{*}\right)_{0}=-0.0159 \pm$ $11720.0014 \%$ (Larsen et al., 2011). (b) Internal mineral isochron of the W-L rim, $1173 \quad\left({ }^{26} \mathrm{Al} /{ }^{27} \mathrm{Al}\right)_{0}=(4.5 \pm 0.4) \times 10^{-5}$ and $\left(\delta^{26} \mathrm{Mg}^{*}\right)_{0}=-0.05 \pm 0.05 \%$. Errors are $2 \sigma . \mathrm{W}-\mathrm{L}$, 1174 the Wark-Lovering rim; Di, diopside; Fas, fassaite; Mel, melilite; Sp, spinel.

1175 

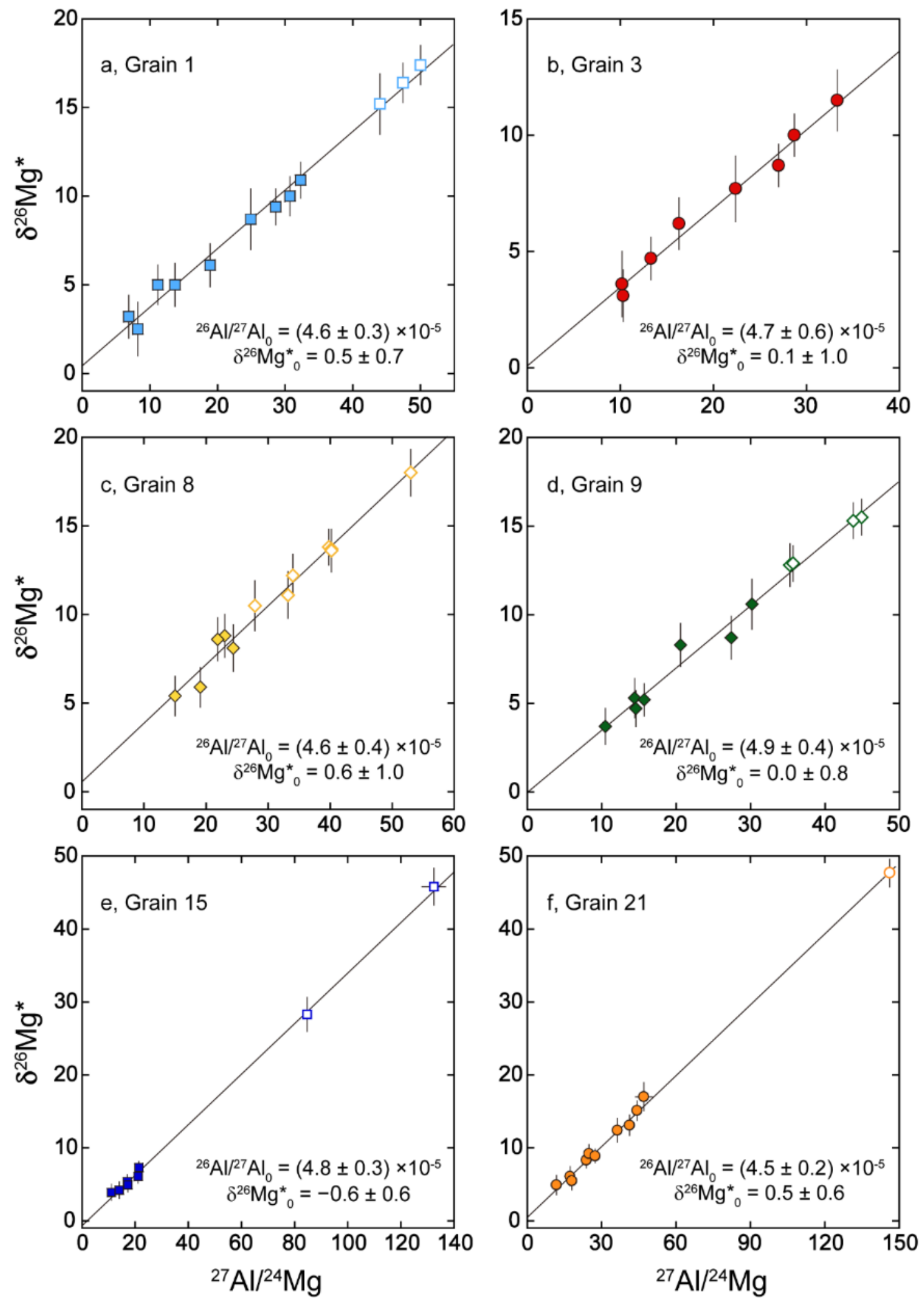

Figure 7. ${ }^{26} \mathrm{Al}-{ }^{26} \mathrm{Mg}$ isochrons for individual reversely zoned melilite crystals in 1178 V2-01. Solid symbols correspond to inner zones having ${ }^{16} \mathrm{O}$-poor compositions and 
1179 open symbols correspond to outer zones with increasingly ${ }^{16} \mathrm{O}$-rich compositions with 1180 decreasing Åk contents. Errors are $2 \sigma$.

1181 
Åk (mol \%)
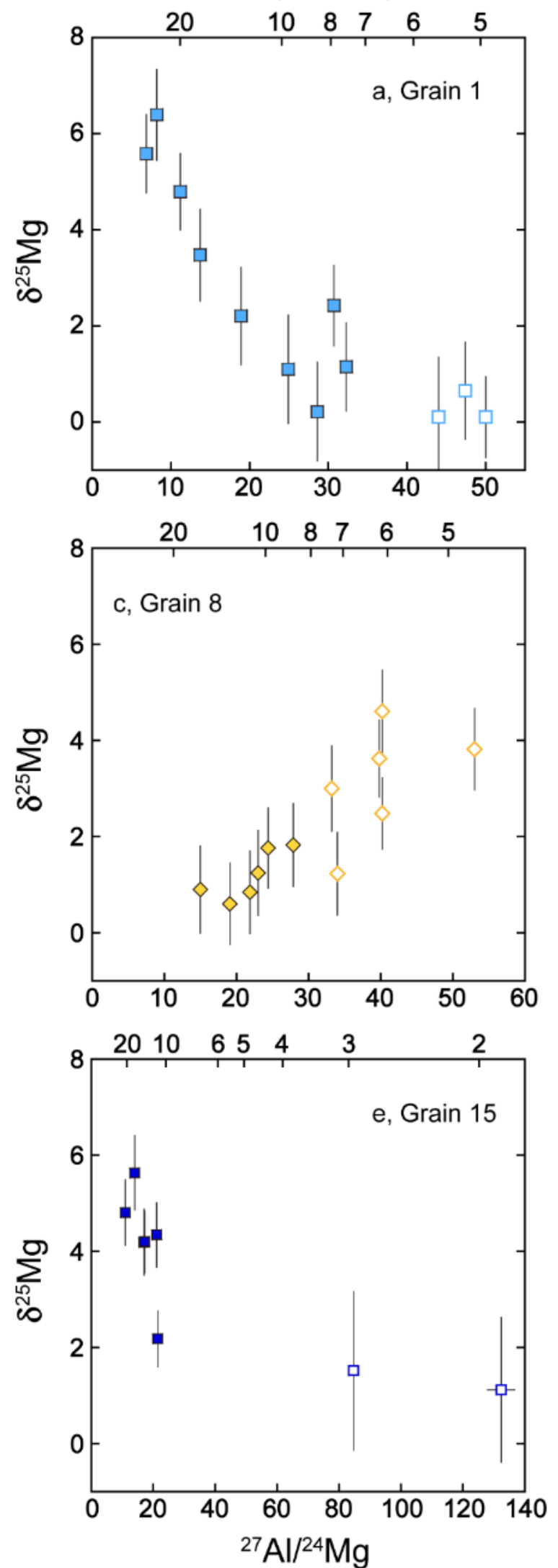

Åk (mol \%)
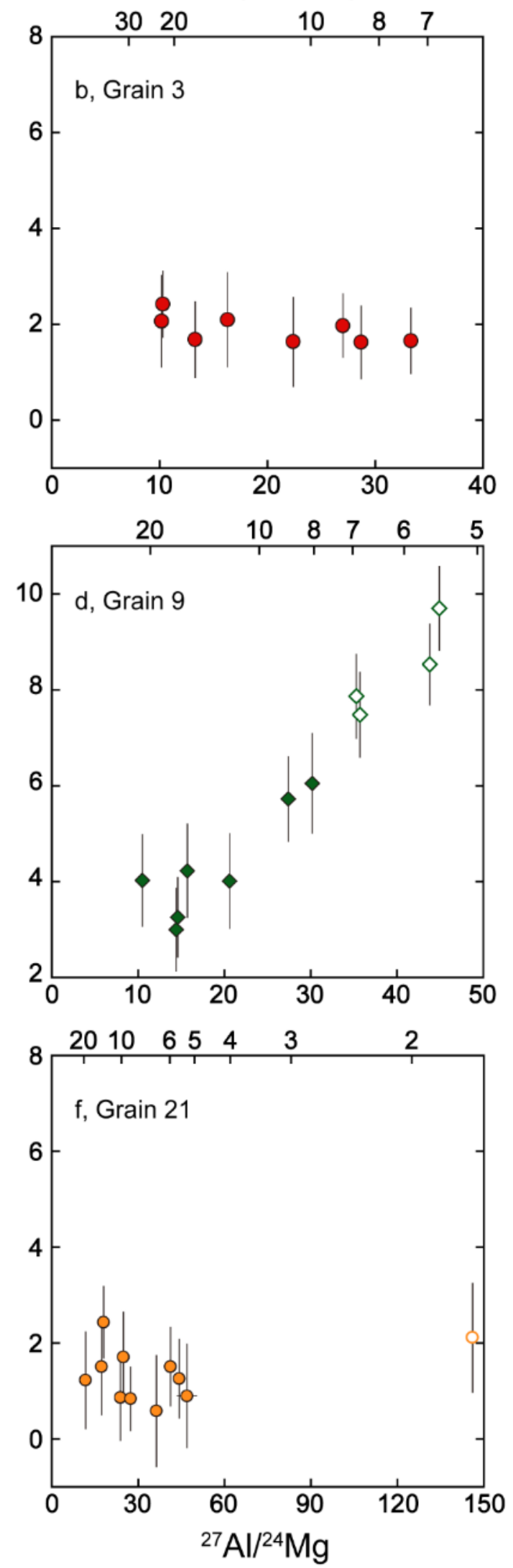
1183 Figure 8. Relationships between the $\delta^{25} \mathrm{Mg}$ values and chemical compositions for each 1184 melilite crystal. Solid symbols correspond to inner zones having ${ }^{16} \mathrm{O}$-poor 1185 compositions and open symbols correspond to outer zones with increasingly ${ }^{16} \mathrm{O}$-rich 1186 compositions with decreasing Åk contents. Errors are $2 \sigma$.

1187 


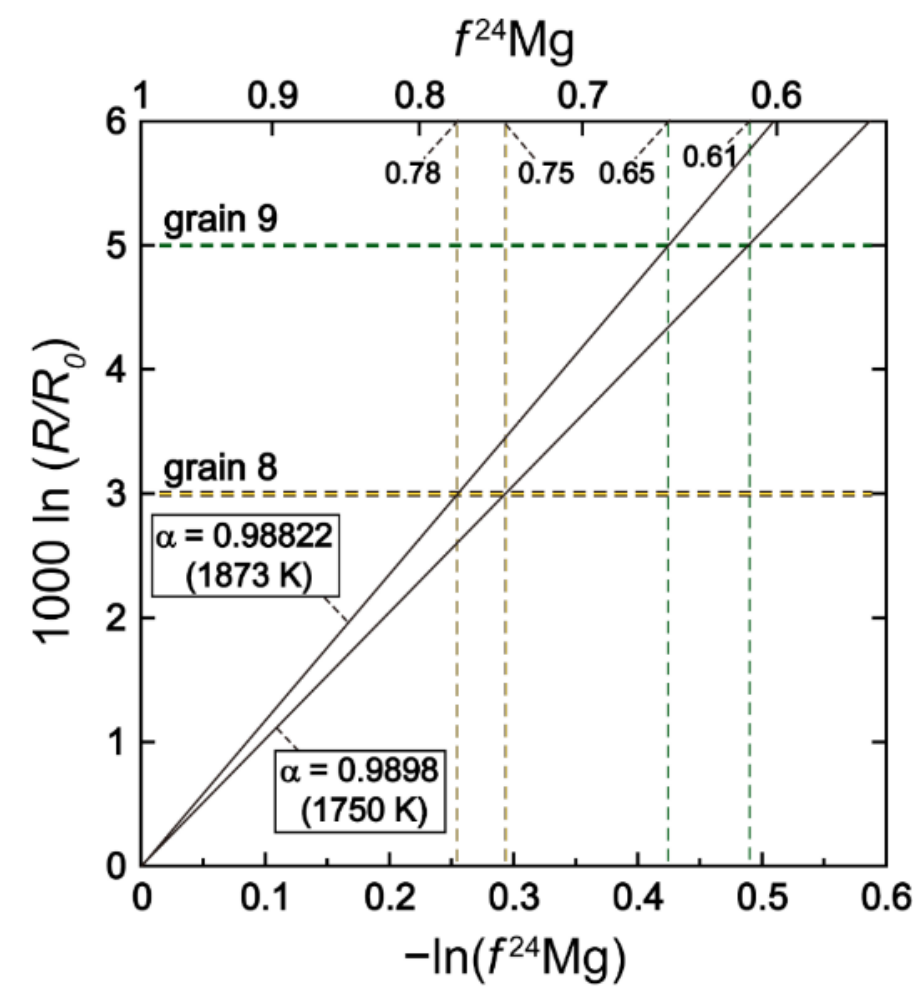

1188

1189

1190

1191

1192

1193

1194

1195

1196
Figure 9. Relationships between elemental and isotopic fractionation during evaporation following the Rayleigh law plotted as $1000 \times \ln \left(R / R_{0}\right)$ versus $-\ln f^{24} \mathrm{Mg}$ and $f{ }^{24} \mathrm{Mg}$, where $R$ is ${ }^{25} \mathrm{Mg} /{ }^{24} \mathrm{Mg}$ in the residual melt, $R_{0}$ is ${ }^{25} \mathrm{Mg} /{ }^{24} \mathrm{Mg}$ in the melt before evaporation, and $f$ is the fraction of ${ }^{24} \mathrm{Mg}$ remaining in the residual melt. The kinetic isotopic fractionation factor, $\alpha$, is from Richter et al. (2007). Observed magnesium isotopic fractionation for grain 8 of $\ln \left(R / R_{0}\right) \sim 3 \%$ and that for grain 9 of $\ln \left(R / R_{0}\right) \sim 5 \%$ are indicated by horizontal dashed lines. 
(1) Spinel formation in ${ }^{16} \mathrm{O}$-rich reservoir<smiles>[CH]C=C[Hg]</smiles>

(2) Melilite formation in a reservoir changing from ${ }^{16} \mathrm{O}$-poor to ${ }^{16} \mathrm{O}$-rich

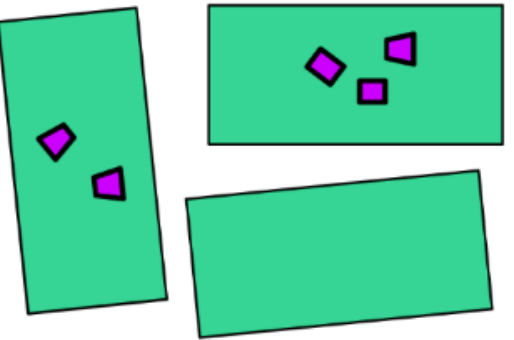

(3) Melilite accumulation

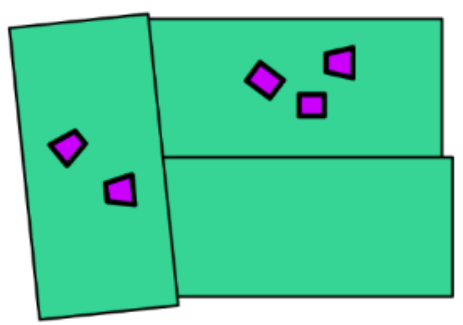

(4) W-L rim formation in ${ }^{16} \mathrm{O}$-rich reservoir

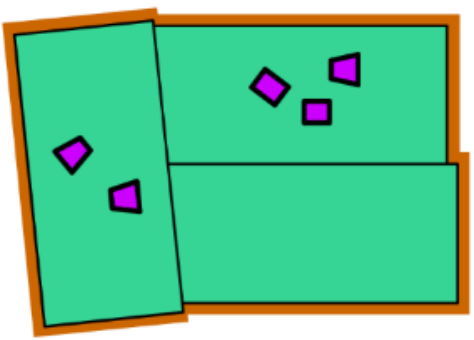

1198 Figure 10. Schematic scenario for the formation of V2-01. The formation sequence of the CAI is described as follows: (1) Spinel crystals formed in a ${ }^{16} \mathrm{O}$-rich reservoir. Fassaite crystals might also form at this stage. (2) Reversely zoned melilite crystals (green rectangles) formed in a variable oxygen isotope reservoir that changed from ${ }^{16} \mathrm{O}$-poor to ${ }^{16} \mathrm{O}$-rich. Some of melilite crystals enclose pre-existing spinel crystals (purple). (3) Melilite crystals accumulated to form a fluffy CAI. (4) W-L rim minerals 
1204 formed in a ${ }^{16} \mathrm{O}$-rich reservoir. Age differences among stages are shown in Fig. 11. 1205 


\section{Age from canonical (Myr)}

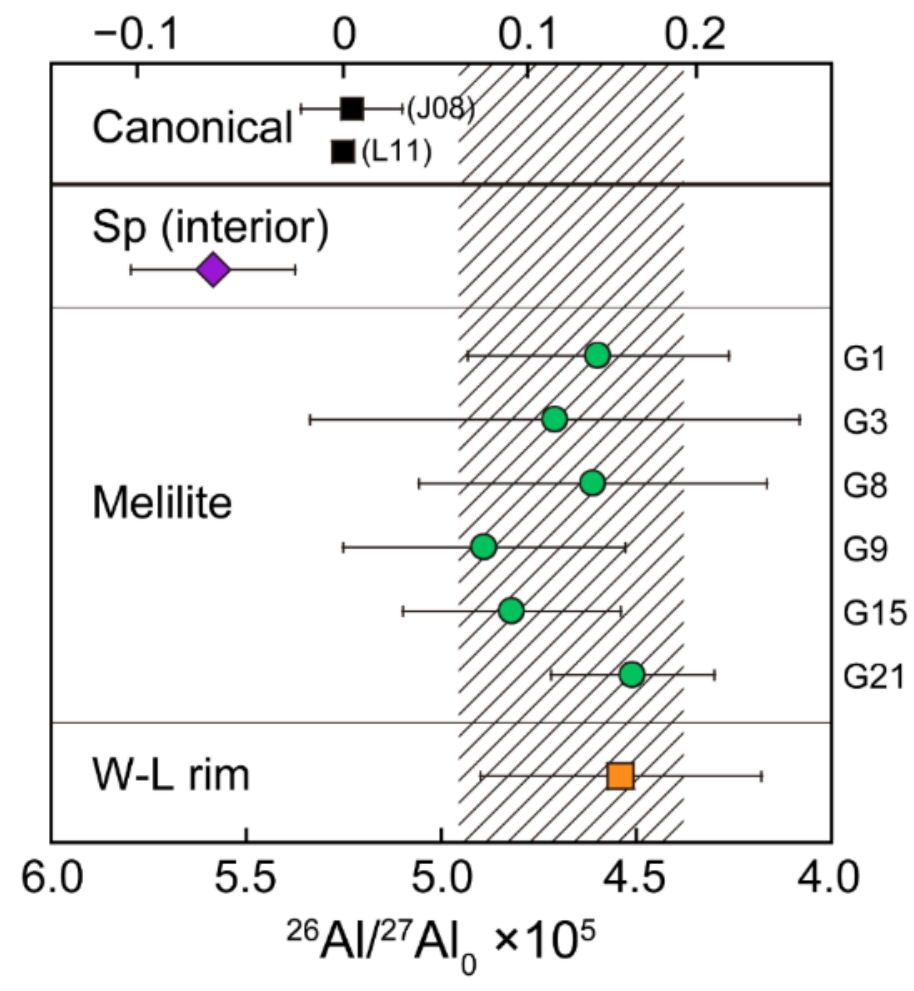

Figure 11. Comparisons of $\left({ }^{26} \mathrm{Al}{ }^{27} \mathrm{Al}\right)_{0}$ values among spinel in the CAI interior, six 1208 reversely zoned melilite crystals, and the W-L rim. Canonical values are from 1209 Jacobsen et al. (2008), shown as J08 and Larsen et al. (2011), shown as L11. The age 1210 from canonical, upper $\mathrm{x}$ axis, was calculated using the $\left({ }^{26} \mathrm{Al} /{ }^{27} \mathrm{Al}\right)_{0}$ value by Larsen et al. (2011). Errors are $2 \sigma$. The width of the shaded area covers $\pm 2 \mathrm{SD}$ of $\left({ }^{26} \mathrm{Al} /{ }^{27} \mathrm{Al}\right)_{0}$ values for the six melilite crystals and for the W-L rim. 